\title{
Flexible synthesis of isomeric pyranoindolones and evaluation of cytotoxicity towards HeLa cells
}

\author{
J C JEYAVEERAN ${ }^{\mathrm{a}}$, CHANDRASEKAR PRAVEEN $^{\mathrm{b}, *}$, Y ARUN $^{\mathrm{c}}$, A A M PRINCE $^{\mathrm{a}}$ \\ and P T PERUMAL ${ }^{\mathrm{C}}$ \\ ${ }^{a}$ Department of Chemistry, Ramakrishna Mission Vivekananda College, Mylapore, Chennai 600 004, India \\ ${ }^{\mathrm{b}}$ Functional Materials Division, Central Electrochemical Research Institute (CSIR laboratory), \\ Karaikudi 630 006, India \\ ${ }^{\mathrm{c}}$ Organic Chemistry Division, Central Leather Research Institute (CSIR laboratory), Adyar, \\ Chennai 600 020, India \\ e-mail: chandrasekar.praveen@gmail.com
}

MS received 17 November 2015; revised 10 January 2016; accepted 6 March 2016

\begin{abstract}
A hybrid pharmacophore approach for the synthesis of isomeric pyranoindolones was achieved by employing gold(III) chloride-catalyzed cycloisomerization of alkyne-tethered indole carboxylic acids in good to excellent yield. All the synthesized compounds were evaluated for their tumor cell growth inhibitory activity against human cervix adenocarcinoma (HeLa) which revealed that three compounds exhibited activity comparable with the standard cis-platin $\left(\mathrm{IC}_{50}=0.08 \mu \mathrm{M}\right)$. Molecular docking of all the compounds in Vaccinia H1-Related (VHR) Phosphatase receptor also supported that compound 7d as the most active with a free energy of binding as $-8.27 \mathrm{kcal} / \mathrm{mol}$.
\end{abstract}

Keywords. Pyranoindolones; positional isomers; gold catalysis; chemical synthesis; cytotoxicity; molecular docking.

\section{Introduction}

In recent years, homogeneous gold catalysis was frequently applied in medicinal chemistry for the synthesis of bioactive natural products and clinical drugs. ${ }^{1}$ Ever since its first use in homogeneous gold catalysis, the catalytic application of $\mathrm{AuCl}_{3}$ has been used in numerous organic transformations. ${ }^{2}$ Our group was engaged in the development and applications of gold catalyzed methodologies for the synthesis of hetero- and carbocycles. $^{3 \mathrm{a}-\mathrm{j}}$ Towards this end, we have previously communicated the $\mathrm{AuCl}_{3}$ catalyzed cycloisomerization of 3-alkynyl-indole-2-carboxylic acid leading to pyrano[3,4- $b]$ indol-1 $(9 H)$-ones, which exhibited moderate cytotoxicity towards HeLa cells. ${ }^{3 \mathrm{~d}}$ As a logical extension, we envisaged the synthesis of corresponding positional isomer, pyrano[4,3- $b$ ]indol-1 $(5 H)$-ones by utilising 2-alkynyl-indole-3-carboxylic acid instead of 3-alkynyl-indole-2-carboxylic acids (figure 1). At the outset, the success of such a deceptively simple variant could not be taken for granted, since these compounds may show improved levels of cytotoxicity. Surprisingly, the synthesis of these types of compounds has scarcely been investigated. Some rare examples

\footnotetext{
*For correspondence
}

include $\left[\left(\mathrm{Cp}^{*} \mathrm{RhCl}_{2}\right)_{2}\right] / \mathrm{Cu}(\mathrm{OAc})_{2}$ catalyzed oxidative coupling of indole-3-carboxylic acid with internal alkynes, ${ }^{4} \mathrm{Pd}(\mathrm{OAc})_{2} / \mathrm{AgCO}_{3}$ catalyzed annulation of allenes with indole-2-carboxylic acids, ${ }^{5}$ cycloisomerization of indole acetylenic acids by $\pi$-Lewis acid. ${ }^{3 \mathrm{~d}, 6}$ Given the significance of these methodologies, a catalytic protocol that accomplishes the general and flexible synthesis of isomeric pyranoindolones remains to be developed. In this context, we herein report the synthesis and cytotoxic evaluation of pyrano[4,3- $b$ ]indol$1(5 \mathrm{H})$-ones towards HeLa cells. The results of chemical synthesis as well as comparison of the biological data with our previously reported pyrano[3,4- $b]$ indol$1(9 H)$-one scaffolds are disclosed in this paper.

\section{Experimental}

\subsection{Materials and instruments}

All commercially available solvents and reagents were used without further purification. Solutions in organic solvents were dried with anhydrous sodium sulphate. Solvents were evaporated under reduced pressure. Melting points were obtained using open capillaries and are uncorrected. Infrared (IR) spectra were recorded on 


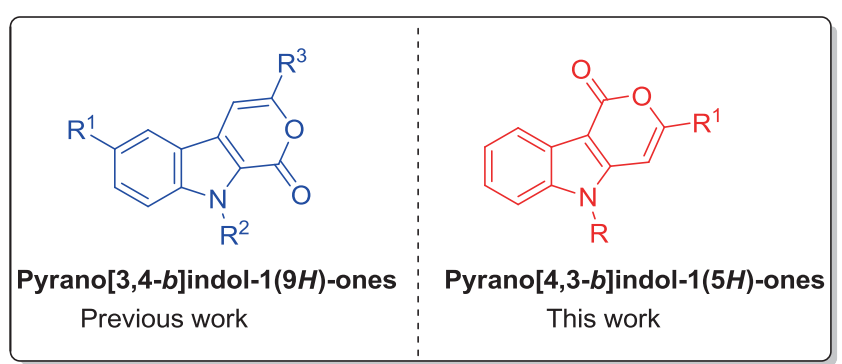

Figure 1. Structures of isomeric pyranoindolones.

a Perkin-Elmer FTIR spectrophotometer as $\mathrm{KBr}$ pellets for solid compounds and neat sample for liquid compounds. ${ }^{1} \mathrm{H}$ and ${ }^{13} \mathrm{C}$ NMR spectra were obtained in DMSO- $d_{6}$ and $\mathrm{CDCl}_{3}$ on a JEOL spectrometer at 500 and $125 \mathrm{MHz}$, respectively. Proton chemical shifts $(\delta)$ are relative to tetramethylsilane (TMS, $\delta=0.00$ ) as internal standard and expressed in parts per million. The number of protons $(n)$ for a given resonance was indicated as $n \mathrm{H}$. Spin multiplicities are given as $\mathrm{s}$ (singlet), d (doublet), $\mathrm{t}$ (triplet), dd (doublet of doublet), dt (doublet of triplet), ddd (doublet of doublet of doublet) and $\mathrm{m}$ (multiplet). Coupling constants $(J)$ are given in hertz. Elemental analyses were recorded using a Thermo Finnigan FLASH EA 1112CHN analyzer.All the compounds gave $\mathrm{C}, \mathrm{H}$ and $\mathrm{N}$ analysis within $\pm 0.5 \%$ of the theoretical values. Column chromatography was performed using a mixture of petroleum ether and ethyl acetate on silica gel (100-200 mesh, SRL, India). Analytical TLC was performed on precoated plastic sheets of silica gel G/UV-254 of $0.2 \mathrm{~mm}$ thickness (MachereyNagel, Germany) using analytical grade solvents and visualized with iodine spray $\left(10 \% \mathrm{w} / \mathrm{w} \mathrm{I}_{2}\right.$ in silica gel), UV light $(\lambda=254$ and $365 \mathrm{~nm})$ and alkaline $\mathrm{KMnO}_{4}$ solution. Human cervical cancer cell line (HeLa) was obtained from National Centre for Cell Science (Pune, India). Cells were cultured in Dulbecco's modified Eagle medium (DMEM) (Sigma Chemical Co.) containing glucose $(5 \mathrm{mM})$ and supplemented with $10 \%$ fetal bovine serum and maintained at $37^{\circ} \mathrm{C}$ in a humidified incubator with an atmosphere of $5 \% \mathrm{CO}_{2}$. The in vitro cytotoxicity of the compounds was evaluated using MTT colourimetric assay. Absorbance (at $\lambda_{\max }$ ) was read on Tenac 200 plate reader at $570 \mathrm{~nm}$. The $\mathrm{IC}_{50}$ values were calculated using the PrismPad computer program (GraphPad Software, Inc., San Diego, CA) and were defined as concentration of drug causing $50 \%$ inhibition in absorbance compared with control (vehicle) cells. All computations for molecular docking studies were carried out on a Dell Desktop D510 personal computer $(2.4 \mathrm{GHz}$ Pentium 4 processor, Intel, Santa Clara, CA) running Red Hat Enterprise Linux Client release 5.5. The time required for each simulation run was on the order of Real $=1 \mathrm{~h} 13 \mathrm{~m} 54.67 \mathrm{~s}, \mathrm{CPU}=1 \mathrm{~h}$ $08 \mathrm{~m} 54.57 \mathrm{~s}$, System $=11.75 \mathrm{~s}$ on the Pentium machine.

\subsection{Methods and Characterization}

2.2a General Procedure for the esterification of indole-2-carboxylic acids $\mathbf{2 a}$ and $\mathbf{2 b}$ : To an ice-cold solution of indole-2-carboxylic acid $(5.0 \mathrm{~g})$ in methanol $(60 \mathrm{~mL})$ was added concentrated sulphuric acid $(5 \mathrm{~mL})$. The reaction mixture was refluxed for $24 \mathrm{~h}$ and concentrated under reduced pressure. To this reaction mixture was added ice-cold water $(50 \mathrm{~mL})$ and extracted with EtOAc $(3 \times 50 \mathrm{~mL})$. The organic layer was dried over anhydrous $\mathrm{Na}_{2} \mathrm{SO}_{4}$, filtered and concentrated to afford analytically pure product ( $98 \%$ yield) which was used for the next step without further purification.

\section{$2.2 \mathrm{~b}$ General procedure for the iodination of indole-} 2-carboxylic acid methyl ester $\mathbf{3} \boldsymbol{a}$ and $\mathbf{3 b}$ : To a solution of indole-2-carboxylic acid methyl ester $(5.0 \mathrm{~g})$ in $15 \mathrm{~mL}$ of DMF was added powdered $\mathrm{KOH}$ (3.0 equiv) and stirred for $15 \mathrm{~min}$. To this mixture was added a solution of iodine (1.1 equiv) in DMF $(15 \mathrm{~mL})$ and stirred for $3 \mathrm{~h}$. After completion of the reaction as indicated by TLC, the reaction mixture was quenched with $10 \% \mathrm{NaHSO}_{3}$ and extracted with EtOAc $(3 \times 30 \mathrm{~mL})$. The EtOAc extract was repeatedly washed with $10 \%$ $\mathrm{Na}_{2} \mathrm{~S}_{2} \mathrm{O}_{3}$ and aqueous ammonia. The combined organic extract was dried over anhydrous $\mathrm{Na}_{2} \mathrm{SO}_{4}$ and concentrated under reduced pressure to afford the pure product (90\% yield) which was used for the next step without further purification.

2.2c General procedure for the $N$-alkylation of 3iodo-indole-2-carboxylic acid methyl ester $4 \boldsymbol{a}, \mathbf{4 b}, \mathbf{4 d}$ and $4 \boldsymbol{e}$ : To a mixture of $\mathrm{NaH}$ (2.0 equiv) in DMF (3 mL) kept at $0^{\circ} \mathrm{C}$ at $\mathrm{N}_{2}$ atmosphere was added a solution of 3-iodo-indole-2-carboxylate (1.0 equiv) in DMF $(2 \mathrm{~mL})$ and stirred for $15 \mathrm{~min}$. To this mixture was added the corresponding alkyl halide (1.2 equiv) and stirred for $3 \mathrm{~h}$ at $0^{\circ} \mathrm{C}$ to room temperature. After completion of the reaction as indicated by TLC, the reaction mixture was quenched with water and extracted with EtOAc $(3 \times 10 \mathrm{~mL})$. The organic layer was dried over anhydrous $\mathrm{Na}_{2} \mathrm{SO}_{4}$, filtered, concentrated and purified by column chromatography on silica gel using petroleum ether/EtOAc to afford the pure product.

2.2c1 1-Methyl-3-iodo-1H-indole-2-carboxylic acid methyl ester (4a): $91 \%$ yield; Yellow solid; M.p. 64$65^{\circ} \mathrm{C}$; IR (KBr): 2925, 2360, 1704, 1455, 1247, 1100 , $741 \mathrm{~cm}^{-1} .{ }^{1} \mathrm{H}$ NMR $\left(500 \mathrm{MHz}, \mathrm{CDCl}_{3}\right): \delta_{\mathrm{H}} 3.97(\mathrm{~s}, 3 \mathrm{H})$; 
$4.05(\mathrm{~s}, 3 \mathrm{H}) ; 7.22(\mathrm{t}, 1 \mathrm{H}, J=6.8 \mathrm{~Hz}) ; 7.32(\mathrm{~d}, 1 \mathrm{H}$, $J=8.4 \mathrm{~Hz}) ; 7.39(\mathrm{t}, 1 \mathrm{H}, J=6.8 \mathrm{~Hz}) ; 7.56(\mathrm{~d}, 1 \mathrm{H}$, $J=7.6 \mathrm{~Hz}) \cdot{ }^{13} \mathrm{C}$ NMR $\left(125 \mathrm{MHz}, \mathrm{CDCl}_{3}\right): \delta_{\mathrm{C}} 33.1$, 51.7, 110.5, 121.5, 124.0, 126.2, 128.8, 130.3, 130.4, 139.0, 161.9. GC-MS: $m / z=315\left[\mathrm{M}^{+}\right]$. Anal. Calcd for $\mathrm{C}_{11} \mathrm{H}_{10} \mathrm{INO}_{2}$ : C, 41.93; H, 3.20; N, 4.45\%. Found: C, 42.11; H, 3.16; N, 4.39\%.

2.2c2 1-Ethyl-3-iodo-1H-indole-2-carboxylic acid methyl ester (4b): $85 \%$ yield; Brown oil; IR (neat): 2928, 1706, 1465, 1218, 1110, $745 \mathrm{~cm}^{-1} .{ }^{1} \mathrm{H}$ NMR $(500 \mathrm{MHz}$, $\left.\mathrm{CDCl}_{3}\right): \delta_{\mathrm{H}} 1.49(\mathrm{t}, 3 \mathrm{H}, J=6.9 \mathrm{~Hz}) ; 3.97(\mathrm{~s}, 3 \mathrm{H}) ; 4.45$ $(\mathrm{q}, 2 \mathrm{H}, J=6.8 \mathrm{~Hz}) ; 7.21(\mathrm{t}, 1 \mathrm{H}, J=6.8 \mathrm{~Hz}) ; 7.34-7.37$ $(\mathrm{m}, 2 \mathrm{H}) ; 7.56(\mathrm{~d}, 1 \mathrm{H}, J=7.6 \mathrm{~Hz}) .{ }^{13} \mathrm{C} \mathrm{NMR}(125 \mathrm{MHz}$, $\left.\mathrm{CDCl}_{3}\right): 15.8,41.0,51.7,110.5,121.5,121.6,124.1$, 126.0, 126.1, 130.5, 138.0, 161.3. GC-MS: $m / z=329$ $\left[\mathrm{M}^{+}\right]$. Anal. Calcd for $\mathrm{C}_{12} \mathrm{H}_{12} \mathrm{INO}_{2}: \mathrm{C}, 43.79 ; \mathrm{H}, 3.67$; N, 4.26\%. Found: C, 43.89; H, 3.65; N, 4.24\%.

2.2c3 3-Iodo-5-methoxy-1-methyl-1H-indole-2-carboxylic acid methyl ester (4d): 92\% yield; Yellow solid; M.p. 107-108 ${ }^{\circ}$; IR (KBr): 2900, 2360, 1692, $1446,1218 \mathrm{~cm}^{-1} .{ }^{1} \mathrm{H}$ NMR $\left(500 \mathrm{MHz}, \mathrm{CDCl}_{3}\right): \delta_{\mathrm{H}}$ 3.89 (s, 3H); $3.96(\mathrm{~s}, 3 \mathrm{H}) ; 4.01(\mathrm{~s}, 3 \mathrm{H}) ; 6.91(\mathrm{~s}, 1 \mathrm{H})$; $7.02(\mathrm{~d}, 1 \mathrm{H}, J=9.1 \mathrm{~Hz}) ; 7.22(\mathrm{~d}, 1 \mathrm{H}, J=9.1 \mathrm{~Hz}) \cdot{ }^{13} \mathrm{C}$ NMR $\left(125 \mathrm{MHz}, \mathrm{CDCl}_{3}\right): \delta_{\mathrm{C}} 32.2,51.6,55.8,103.5$, $111.7,118.1,128.6,130.6,134.4,155.5,161.8$. GCMS: $m / z=345\left[\mathrm{M}^{+}\right]$. Anal. Calcd for $\mathrm{C}_{12} \mathrm{H}_{12} \mathrm{INO}_{3}: \mathrm{C}$, 41.76; H, 3.50; N, 4.06\%. Found: C, 41.91; H, 3.46; N, $4.02 \%$.

2.2c4 3-Iodo-5-methoxy-1-ethyl-1H-indole-2-carboxylic acid methyl ester (4e): $83 \%$ yield; Brown oil; IR (neat): 2919, 1706, 1455, 1204, $830 \mathrm{~cm}^{-1} .{ }^{1} \mathrm{H}$ NMR $\left(500 \mathrm{MHz}, \mathrm{CDCl}_{3}\right): \delta_{\mathrm{H}} 1.47(\mathrm{t}, 3 \mathrm{H}, J=6.8 \mathrm{~Hz}) ; 3.86(\mathrm{~s}$, $3 \mathrm{H}) ; 3.94$ (s, 3H); 4.42 (q, 2H, $J=7.6 \mathrm{~Hz}) ; 6.90$ (d, $1 \mathrm{H}$, $J=2.3 \mathrm{~Hz}) ; 6.99(\mathrm{~d}, 1 \mathrm{H}, J=8.4 \mathrm{~Hz}) ; 7.19(\mathrm{~d}, 1 \mathrm{H}, J=$ $9.1 \mathrm{~Hz}) .{ }^{13} \mathrm{C} \mathrm{NMR}\left(125 \mathrm{MHz}, \mathrm{CDCl}_{3}\right): \delta_{\mathrm{C}} 14.3,41.1$, 55.7, 61.2, 103.6, 111.6, 117.9, 118.0, 127.6, 130.7, 133.2, 155.5, 161.1. GC-MS: $m / z=359\left[\mathrm{M}^{+}\right]$. Anal. Calcd for $\mathrm{C}_{13} \mathrm{H}_{14} \mathrm{INO}_{3}$ : C, 43.47; H, 3.93; N, 3.90\%. Found: C, 43.21; H, 3.97; N, 3.96\%.

2.2d General procedure for the N-alkylation of 3iodo-indole-2-carboxylic acid methyl ester $4 \boldsymbol{c}$, $4 \boldsymbol{f}$ and $4 \boldsymbol{g}$ : To a mixture of $\mathrm{KOH}$ (3.0 equiv) in DMSO ( $3 \mathrm{~mL}$ ) kept at $0^{\circ} \mathrm{C}$ was added, 3-iodo-indole-2-carboxylate (1.0 equiv) and stirred for $30 \mathrm{~min}$. To this mixture was added the corresponding alkyl halide (5.0 equiv) and stirred for $6 \mathrm{~h}$ at $0^{\circ} \mathrm{C}$ to room temperature. After completion of the reaction as indicated by TLC, the reaction mixture was quenched with water and extracted with EtOAc $(3 \times 15 \mathrm{~mL})$. The organic layer was dried over anhydrous $\mathrm{Na}_{2} \mathrm{SO}_{4}$, filtered, concentrated and purified by column chromatography on silica gel using petroleum ether/EtOAc to afford the pure product.

2.2d1 1-Butyl-3-iodo-1H-indole-2-carboxylic acid methyl ester (4c): $74 \%$ yield; Brown oil; IR (neat): 2955, 1710, 1463, 1351, 1245, 1199, 1115, $740 \mathrm{~cm}^{-1} \cdot{ }^{1} \mathrm{H}$ NMR $\left(500 \mathrm{MHz}, \mathrm{CDCl}_{3}\right): \delta_{\mathrm{H}} 0.93(\mathrm{t}, 3 \mathrm{H}, J=7.6 \mathrm{~Hz})$; $1.33-1.37(\mathrm{~m}, 2 \mathrm{H}) ; 1.73-1.76(\mathrm{~m}, 2 \mathrm{H}) ; 3.98(\mathrm{~s}, 3 \mathrm{H})$; $4.53(\mathrm{t}, 2 \mathrm{H}, J=7.6 \mathrm{~Hz}) ; 7.22(\mathrm{t}, 1 \mathrm{H}, J=6.9 \mathrm{~Hz})$; $7.33-7.37(\mathrm{~m}, 2 \mathrm{H}) ; 7.56(\mathrm{~d}, 1 \mathrm{H}, J=7.6 \mathrm{~Hz}) .{ }^{13} \mathrm{C}$ NMR $\left(125 \mathrm{MHz}, \mathrm{CDCl}_{3}\right): \delta_{\mathrm{C}} 13.9,20.2,32.8,45.9$, 51.7, 110.7, 121.5, 124.126.1, 128.2, 130.3, 138.5, 161.8. GC-MS: $m / z=357\left[\mathrm{M}^{+}\right]$. Anal. Calcd for $\mathrm{C}_{14} \mathrm{H}_{16} \mathrm{INO}_{2}$ : C, 47.08; H, 4.52; N, 3.92\%. Found: C, $47.21 ; \mathrm{H}, 4.49 ; \mathrm{N}, 3.85 \%$.

2.2d2 3-Iodo-5-methoxy-1-butyl-1H-indole-2-carboxylic acid methyl ester (4f): 72\% yield; Colourless solid; M.p. 96-98 ${ }^{\circ}$ C; IR (KBr): 2952, 1706, 1500, $1254,1204 \mathrm{~cm}^{-1} \cdot{ }^{1} \mathrm{H}$ NMR $\left(500 \mathrm{MHz}, \mathrm{CDCl}_{3}\right): \delta_{\mathrm{H}}$ $0.92(\mathrm{t}, 3 \mathrm{H}, J=7.6 \mathrm{~Hz}) ; 1.29-1.36(\mathrm{~m}, 2 \mathrm{H}) ; 1.69-1.75$ $(\mathrm{m}, 2 \mathrm{H}) ; 3.89(\mathrm{~s}, 3 \mathrm{H}) ; 3.96(\mathrm{~s}, 3 \mathrm{H}) ; 4.50(\mathrm{t}, 2 \mathrm{H}, J=$ $6.9 \mathrm{~Hz}) ; 6.92(\mathrm{~d}, 1 \mathrm{H}, J=2.2 \mathrm{~Hz}) ; 7.03\left(\mathrm{dd}, 1 \mathrm{H}, J_{1}=\right.$ $\left.2.3 \mathrm{~Hz}, J_{2}=9.1 \mathrm{~Hz}\right) ; 7.24(\mathrm{~d}, 1 \mathrm{H}, J=9.1 \mathrm{~Hz}) .{ }^{13} \mathrm{C}$ NMR $\left(125 \mathrm{MHz}, \mathrm{CDCl}_{3}\right): \delta_{\mathrm{C}} 13.9,20.2,33.0,46.0$, 51.6, 55.8, 103.6, 111.9, 118.0, 128.1, 130.6, 133.8, 155.5, 161.7. GC-MS: $m / z=387\left[\mathrm{M}^{+}\right]$. Anal. Calcd for $\mathrm{C}_{15} \mathrm{H}_{18} \mathrm{INO}_{3}$ : C, 46.53; H, 4.69; N, 3.62\%. Found: C, $46.81 ; \mathrm{H}, 4.65 ; \mathrm{N}, 3.55 \%$.

2.2d3 Methyl-1-benzyl-3-iodo-5-methoxy-1H-indole2-carboxylate (4g): $78 \%$ yield; Colourless solid; M.p. $98-100^{\circ} \mathrm{C}$; IR (KBr): 2938, 2360, 1706, 1500, $1255,1206 \mathrm{~cm}^{-1} .{ }^{1} \mathrm{H} \mathrm{NMR}\left(500 \mathrm{MHz}, \mathrm{CDCl}_{3}\right): \delta_{\mathrm{H}} 3.89$ $(\mathrm{s}, 3 \mathrm{H}) ; 3.90(\mathrm{~s}, 3 \mathrm{H}) ; 5.78(\mathrm{~s}, 2 \mathrm{H}) ; 6.96(\mathrm{~d}, 1 \mathrm{H}, J=$ $2.3 \mathrm{~Hz}) ; 6.99-7.02(\mathrm{~m}, 3 \mathrm{H}) ; 7.20-7.26(\mathrm{~m}, 4 \mathrm{H}) .{ }^{13} \mathrm{C}$ NMR $\left(125 \mathrm{MHz}, \mathrm{CDCl}_{3}\right): \delta_{\mathrm{C}} 49.3,51.7,55.8,103.7$, $112.2,118.4,126.1,127.4,128.4,128.7,128.9,130.9$, 134.2, 137.9, 155.8, 161.6. GC-MS: $m / z=421\left[\mathrm{M}^{+}\right]$. Anal. Calcd for $\mathrm{C}_{18} \mathrm{H}_{16} \mathrm{INO}_{3}: \mathrm{C}, 51.32 ; \mathrm{H}, 3.83 ; \mathrm{N}$, $3.33 \%$. Found: C, 51.50; H, 3.79; N, 3.25\%.

$2.2 \mathrm{e}$ General procedure for the synthesis of 3-ethynylindole-2-carboxylic acid methyl ester 5a-j: To a mixture of 3-iodo-indole-2-carboxylic acid methyl ester $(1.0 \mathrm{mmol}), \mathrm{Pd}\left(\mathrm{Ph}_{3} \mathrm{P}\right)_{2} \mathrm{Cl}_{2}(5.0 \mathrm{~mol} \%)$ and $\mathrm{CuI}$ (5.0 mol\%) under $\mathrm{N}_{2}$ atmosphere was added triethylamine $(5 \mathrm{~mL})$ and stirred for $15 \mathrm{~min}$. To this reaction mixture was added the appropriate terminal alkyne $(1.1 \mathrm{mmol})$ and stirred at room temperature for $6 \mathrm{~h}$. After completion of the reaction as indicated by TLC, the reaction mixture was quenched with water $(50 \mathrm{~mL})$ 
and extracted with EtOAc $(3 \times 15 \mathrm{~mL})$. The organic layer was dried over anhydrous $\mathrm{Na}_{2} \mathrm{SO}_{4}$, filtered, concentrated and purified by column chromatography on silica gel using petroleum ether/EtOAc to afford the pure product.

2.2e1 1-Methyl-3-phenylethynyl-1H-indole-2-carboxylic acid methyl ester (5a): $88 \%$ yield; Brown paste; IR (neat): 2379, 1707, 1472, 1268, 1119, $745 \mathrm{~cm}^{-1} .{ }^{1} \mathrm{H}$ NMR $\left(500 \mathrm{MHz}, \mathrm{CDCl}_{3}\right): \delta_{\mathrm{H}} 4.02(\mathrm{~s}, 3 \mathrm{H}) ; 4.03(\mathrm{~s}, 3 \mathrm{H})$; $7.27(\mathrm{t}, 1 \mathrm{H}, J=7.6 \mathrm{~Hz}) ; 7.32-7.41(\mathrm{~m}, 5 \mathrm{H}) ; 7.64(\mathrm{~d}$, $2 \mathrm{H}, J=7.6 \mathrm{~Hz}) ; 7.91(\mathrm{~d}, 1 \mathrm{H}, J=8.4 \mathrm{~Hz}) .{ }^{13} \mathrm{C} \mathrm{NMR}$ $\left(125 \mathrm{MHz}, \mathrm{CDCl}_{3}\right): \delta_{\mathrm{C}} 32.3,51.9,83.2,95.7,105.0$, $110.5,121.4,121.7,124.2,126.0,127.9,128.1,128.5$, 128.9, 131.6, 138.4, 162.1. MS (EI): $m / z=289\left[\mathrm{M}^{+}\right]$. Anal. Calcd for $\mathrm{C}_{19} \mathrm{H}_{15} \mathrm{NO}_{2}$ : C, 78.87; H, 5.23; N, 4.84\%. Found: C, 79.10; H, 5.15; N, 4.76\%.

2.2e2 1-Ethyl-3-phenylethynyl-1H-indole-2-carboxylic acid methyl ester (5b): $86 \%$ yield; Brown oil; IR (neat): 2976, 1701, 1469, 1247, $1124 \mathrm{~cm}^{-1} .{ }^{1} \mathrm{H}$ NMR $\left(500 \mathrm{MHz}, \mathrm{CDCl}_{3}\right): \delta_{\mathrm{H}} 1.52(\mathrm{t}, 3 \mathrm{H}, J=6.8 \mathrm{~Hz}) ; 4.05$ $(\mathrm{s}, 3 \mathrm{H}) ; 4.51(\mathrm{q}, 2 \mathrm{H}, J=6.9 \mathrm{~Hz}) ; 7.27-7.31(\mathrm{~m}, 1 \mathrm{H})$; $7.36(\mathrm{~d}, 1 \mathrm{H}, J=7.6 \mathrm{~Hz}) ; 7.39-7.44(\mathrm{~m}, 4 \mathrm{H}) ; 7.65(\mathrm{~d}$, $2 \mathrm{H}, J=7.6 \mathrm{~Hz}) ; 7.95(\mathrm{~d}, 1 \mathrm{H}, J=8.4 \mathrm{~Hz}) .{ }^{13} \mathrm{C} \mathrm{NMR}$ $\left(125 \mathrm{MHz}, \mathrm{CDCl}_{3}\right): \delta_{\mathrm{C}} 15.7,40.3,51.9,83.3,95.5$, $110.5,121.4,121.9,124.3,126.0,126.1,128.0,128.1$, 128.5, 131.5, 131.6, 137.5, 161.5. MS (EI): $m / z=303$ $\left[\mathrm{M}^{+}\right]$. Anal. Calcd for $\mathrm{C}_{20} \mathrm{H}_{17} \mathrm{NO}_{2}: \mathrm{C}, 79.19 ; \mathrm{H}, 5.65$; N, 4.62\%. Found: C, 79.31; H, 5.62; N, 4.57\%.

2.2e3 1-Butyl-3-phenylethynyl-1H-indole-2-carboxylic acid methyl ester (5c): $79 \%$ yield; Yellow liquid; IR (neat): 2926, 1708, 1463, 1359, 1244, 1200, 1124, $745 \mathrm{~cm}^{-1} .{ }^{1} \mathrm{H}$ NMR $\left(500 \mathrm{MHz}, \mathrm{CDCl}_{3}\right): \delta_{\mathrm{H}} 0.93(\mathrm{t}, 3 \mathrm{H}$, $J=6.9 \mathrm{~Hz}) ; 1.33-1.40$ (m, 2H); $1.75-1.79$ (m, 2H); $4.02(\mathrm{~s}, 3 \mathrm{H}) ; 4.55(\mathrm{t}, 2 \mathrm{H}, J=7.6 \mathrm{~Hz}) ; 7.28-7.33(\mathrm{~m}$, $1 \mathrm{H}) ; 7.38(\mathrm{~d}, 1 \mathrm{H}, J=7.6 \mathrm{~Hz}) ; 7.41-7.50(\mathrm{~m}, 4 \mathrm{H})$; $7.69(\mathrm{~d}, 2 \mathrm{H}, J=7.6 \mathrm{~Hz}) ; 8.00(\mathrm{~d}, 1 \mathrm{H}, J=8.4 \mathrm{~Hz}) .{ }^{13} \mathrm{C}$ NMR $\left(125 \mathrm{MHz}, \mathrm{CDCl}_{3}\right): \delta_{\mathrm{C}} 13.6,20.1,32.6,45.6$, $52.0,83.7,95.6,110.7,121.6,124.5,126.1,126.3$, 127.9, 128.2, 128.6, 131.6, 131.8, 137.7, 161.7. MS (EI): $m / z=331\left[\mathrm{M}^{+}\right]$. Anal. Calcd for $\mathrm{C}_{22} \mathrm{H}_{21} \mathrm{NO}_{2}: \mathrm{C}$, 79.73; H, 6.39; N, 4.23\%. Found: C, 79.51; H, 6.44; N, $4.30 \%$.

2.2e4 5-Methoxy-1-methyl-3-phenylethynyl-1H-indole2-carboxylic acid methyl ester (5d): $90 \%$ yield; Orange solid; M.p. $182-184{ }^{\circ} \mathrm{C}$; IR (KBr): 2919, 1692, 1498, 1450, 1190, $878 \mathrm{~cm}^{-1}$. ${ }^{1} \mathrm{H}$ NMR $(500 \mathrm{MHz}$, $\left.\mathrm{CDCl}_{3}\right): \delta_{\mathrm{H}} 3.91(\mathrm{~s}, 3 \mathrm{H}) ; 4.00(\mathrm{~s}, 3 \mathrm{H}) ; 4.04(\mathrm{~s}, 3 \mathrm{H})$; $7.06\left(\mathrm{dd}, 1 \mathrm{H}, J_{1}=2.3 \mathrm{~Hz}, J_{2}=9.1 \mathrm{~Hz}\right) ; 7.33-7.39(\mathrm{~m}$,
$3 \mathrm{H}) ; 7.60(\mathrm{~d}, 2 \mathrm{H}, J=6.9 \mathrm{~Hz}) \cdot{ }^{13} \mathrm{C} \mathrm{NMR}(125 \mathrm{MHz}$, $\left.\mathrm{CDCl}_{3}\right): \delta_{\mathrm{C}} 32.5,51.8,55.8,83.2,95.5,101.5,104.2$, 111.5, 117.7, 124.2, 128.0, 128.4, 129.0, 131.5, 133.9, 155.5, 162.1. MS (EI): $m / z=319\left[\mathrm{M}^{+}\right]$. Anal. Calcd for $\mathrm{C}_{20} \mathrm{H}_{17} \mathrm{NO}_{3}$ : C, 75.22; H, 5.37; N, 4.39\%. Found: C, $75.01 ; \mathrm{H}, 5.33 ; \mathrm{N}, 3.33 \%$.

2.2e5 5-Methoxy-1-ethyl-3-phenylethynyl-1H-indole2-carboxylic acid methyl ester (5e): 84\% yield; Brown paste; IR (neat): 2340, 1704, 1438, $1209 \mathrm{~cm}^{-1}$. ${ }^{1} \mathrm{H}$ NMR $\left(500 \mathrm{MHz}, \mathrm{CDCl}_{3}\right): \delta_{\mathrm{H}} 1.39(\mathrm{t}, 3 \mathrm{H}, J=$ $6.9 \mathrm{~Hz}) ; 3.90(\mathrm{~s}, 3 \mathrm{H}) ; 3.91(\mathrm{~s}, 3 \mathrm{H}) ; 4.01(\mathrm{~s}, 3 \mathrm{H}) ; 4.59$ (q, $2 \mathrm{H}, J=6.9 \mathrm{~Hz}) ; 7.05-7.07(\mathrm{~m}, 1 \mathrm{H}) ; 7.24(\mathrm{~s}, 1 \mathrm{H}) ; 7.30$ $7.39(\mathrm{~m}, 4 \mathrm{H}) ; 7.58-7.60(\mathrm{~d}, 2 \mathrm{H}, J=8.4 \mathrm{~Hz}) .{ }^{13} \mathrm{C}$ NMR $\left(125 \mathrm{MHz}, \mathrm{CDCl}_{3}\right): \delta_{\mathrm{C}} 15.7,404,51.8,55.8,83.2$, $95.4,101.6,111.5,117.7,124.2,128.0,128.2,128.6$, 131.4, 131.5, 132.9, 155.5, 161.9. MS (EI): $m / z=333$ $\left[\mathrm{M}^{+}\right]$. Anal. Calcd for $\mathrm{C}_{21} \mathrm{H}_{19} \mathrm{NO}_{3}$ : C, 75.66; H, 5.74; N, 4.20\%. Found: C, 75.51; H, 5.70; N, 4.15\%.

2.2e6 5-Methoxy-1-butyl-3-phenylethynyl-1H-indole2-carboxylic acid methyl ester (5f): 72\% yield; Brown paste; IR (neat): 2938, 2360, 1706, 1446, 1203, $745 \mathrm{~cm}^{-1}$. ${ }^{1} \mathrm{H}$ NMR $\left(500 \mathrm{MHz}, \mathrm{CDCl}_{3}\right): \delta_{\mathrm{H}} 0.93(\mathrm{t}, 3 \mathrm{H}$, $J=7.6 \mathrm{~Hz}) ; 1.32-1.37$ (m, 2H); $1.74-1.77$ (m, 2H); $3.91(\mathrm{~s}, 3 \mathrm{H}) ; 4.00(\mathrm{~s}, 3 \mathrm{H}) ; 4.54(\mathrm{t}, 2 \mathrm{H}, J=7.6 \mathrm{~Hz})$; $7.05\left(\mathrm{dd}, 1 \mathrm{H}, J_{1}=2.3 \mathrm{~Hz}, J_{2}=9.2 \mathrm{~Hz}\right) ; 7.22(\mathrm{~d}, 1 \mathrm{H}$, $J=3.05 \mathrm{~Hz}) ; 7.29-7.37$ (m, 4H); 7.59 (d, 2H, $J=$ $6.8 \mathrm{~Hz}) .{ }^{13} \mathrm{C} \mathrm{NMR}\left(125 \mathrm{MHz}, \mathrm{CDCl}_{3}\right): \delta_{\mathrm{C}} 13.9,20.2$, $32.8,45.3,51.9,55.8,83.3,95.5,101.5,104.3,111.8$, 117.7, 124.2, 128.0, 128.4, 128.5, 128.6, 131.5, 133.3, 155.4, 161.9. MS (EI): $m / z=361\left[\mathrm{M}^{+}\right]$. Anal. Calcd for $\mathrm{C}_{23} \mathrm{H}_{23} \mathrm{NO}_{3}$ : C, 76.43; H, 6.41; N, 3.88\%. Found: C, $76.61 ; \mathrm{H}, 6.36 ; \mathrm{N}, 3.81 \%$.

2.2e7 5-Methoxy-1-benzyl-3-phenylethynyl-1H-indole2-carboxylic acid methyl ester (5g): $85 \%$ yield; Brown solid; M.p. $100-102^{\circ} \mathrm{C}$; IR (KBr): 2945,1705 , 1450, 1239, 1201, $692 \mathrm{~cm}^{-1} .{ }^{1} \mathrm{H}$ NMR $(500 \mathrm{MHz}$, $\left.\mathrm{CDCl}_{3}\right): \delta_{\mathrm{H}} 3.91(\mathrm{~s}, 3 \mathrm{H}) ; 3.96(\mathrm{~s}, 3 \mathrm{H}) ; 5.82(\mathrm{~s}, 2 \mathrm{H})$; 7.01-7.04 (m, 2H); 7.19-7.28 (m, 6H); 7.32-7.40 (m, $4 \mathrm{H} ; 7.61(\mathrm{~d}, 1 \mathrm{H}, J=6.8 \mathrm{~Hz}) .{ }^{13} \mathrm{C}$ NMR $(125 \mathrm{MHz}$, $\left.\mathrm{CDCl}_{3}\right): \delta_{\mathrm{C}} 48.6,51.9,55.8,83.1,95.8,101.7,105.1$, $112.1,118.0,124.1,126.2,127.4,128.1,128.5,128.7$, $128.9,129.1,131.6,133.7,137.8,155.7,161.7 . \mathrm{MS}$ (EI): $m / z=395\left[\mathrm{M}^{+}\right]$. Anal. Calcd for $\mathrm{C}_{26} \mathrm{H}_{21} \mathrm{NO}_{3}: \mathrm{C}$, 78.97; H, 5.35; N, 3.54\%. Found: C, 79.11; H, 5.27; N, $3.44 \%$.

2.2e8 Methyl-3-(hex-1-ynyl)-1H-indole-2-carboxylate (5h): $67 \%$ yield; Yellow solid; M.p. $98-99{ }^{\circ} \mathrm{C}$; IR (KBr): 3317, 1692, 1450, 1217, $736 \mathrm{~cm}^{-1}$. ${ }^{1} \mathrm{H}$ NMR 
$\left(500 \mathrm{MHz}, \mathrm{CDCl}_{3}\right): \delta_{\mathrm{H}} 0.99(\mathrm{t}, 3 \mathrm{H}, J=6.9 \mathrm{~Hz}) ; 1.56-$ $1.61(\mathrm{~m}, 2 \mathrm{H}) ; 1.65-1.70(\mathrm{~m}, 2 \mathrm{H}) ; 2.58(\mathrm{t}, 2 \mathrm{H}, J=$ $6.9 \mathrm{~Hz}) ; 4.00(\mathrm{~s}, 3 \mathrm{H}) ; 7.20(\mathrm{t}, 1 \mathrm{H}, J=6.9 \mathrm{~Hz}) ; 7.34$ $(\mathrm{t}, 1 \mathrm{H}, J=8.4 \mathrm{~Hz}) ; 7.38(\mathrm{~d}, 1 \mathrm{H}, J=7.6 \mathrm{~Hz}) ; 7.78(\mathrm{~d}$, $1 \mathrm{H}, J=7.6 \mathrm{~Hz}) ; 9.25(\mathrm{~s}, 1 \mathrm{H}) .{ }^{13} \mathrm{C} \mathrm{NMR}(125 \mathrm{MHz}$, $\left.\mathrm{CDCl}_{3}\right): \delta_{\mathrm{C}} 13.8,19.7,22.0,31.0,52.2,72.8,97.5$, 105.2, 112.0, 121.2, 121.8, 126.2, 127.4, 129.6, 135.6, 162.2. MS (EI): $m / z=255\left[\mathrm{M}^{+}\right]$. Anal. Calcd for $\mathrm{C}_{16} \mathrm{H}_{17} \mathrm{NO}_{2}$ : C, 75.27; H, 6.71; N, 5.49\%. Found: $\mathrm{C}$, $75.51 ; \mathrm{H}, 6.66 ; \mathrm{N}, 5.41 \%$.

2.2e9 Methyl-3-(2-phenylethynyl)-1H-indole-2-carboxylate (5i): $85 \%$ yield; Brown solid; M.p. $188-189{ }^{\circ} \mathrm{C}$; IR (KBR): $3298,1673,1455,1252,740 \mathrm{~cm}^{-1} .{ }^{1} \mathrm{H}$ NMR $\left(500 \mathrm{MHz}, \mathrm{CDCl}_{3}\right): \delta_{\mathrm{H}} 4.05(\mathrm{~s}, 3 \mathrm{H}) ; 7.25(\mathrm{t}, 1 \mathrm{H}, J=$ $7.6 \mathrm{~Hz}) ; 7.34-7.40(\mathrm{~m}, 4 \mathrm{H}) ; 7.43(\mathrm{~d}, 1 \mathrm{H}, J=7.6 \mathrm{~Hz})$; $7.61(\mathrm{~d}, 2 \mathrm{H}, J=7.6 \mathrm{~Hz}) ; 7.89(\mathrm{~d}, 1 \mathrm{H}, J=7.6 \mathrm{~Hz}) .{ }^{13} \mathrm{C}$ NMR $\left(125 \mathrm{MHz}, \mathrm{CDCl}_{3}\right): \delta_{\mathrm{C}} 52.4,82.1,96.1,104.3$, $112.1,121.6,121.8,123.8,126.5,128.0,128.3,128.4$, 129.2, 131.7, 135.6, 161.9\%. MS (EI): $m / z=275$ $\left[\mathrm{M}^{+}\right]$. Anal. Calcd for $\mathrm{C}_{18} \mathrm{H}_{13} \mathrm{NO}_{2}$ : C, 78.53; H, 4.76; $\mathrm{N}, 5.09 \%$. Found: C, 78.85; H, 4.72; N, 5.02\%.

2.2e10 5-Methoxy-3-phenylethynyl-1H-indole-2-carboxylic acid methyl ester (5j): $87 \%$ yield; Brown solid; M.p. 202-203 ${ }^{\circ}$; IR (KBr): 3289, 1687, 1469 , 1209, $1020 \mathrm{~cm}^{-1} .{ }^{1} \mathrm{H}$ NMR $\left(500 \mathrm{MHz}, \mathrm{CDCl}_{3}+\right.$ DMSO-d $\left.{ }_{6}\right): \delta_{\mathrm{H}} 3.79(\mathrm{~s}, 3 \mathrm{H}) ; 3.90(\mathrm{~s}, 3 \mathrm{H}) ; 6.89(\mathrm{~d}, 1 \mathrm{H}$, $J=9.1 \mathrm{~Hz}) ; 7.09$ (s, 1H); 7.23-7.30 (m, 4H); 7.50 (d, $2 \mathrm{H}, J=6.9 \mathrm{~Hz}) ; 10.85(\mathrm{~s}, 1 \mathrm{H}) .{ }^{13} \mathrm{C} \mathrm{NMR}(125 \mathrm{MHz}$, $\mathrm{CDCl}_{3}+$ DMSO- $\left.d_{6}\right): \delta_{\mathrm{C}} 47.2,50.9,78.1,90.6,96.3$, 97.9, 109.0, 112.8, 119.2, 123.2, 123.6, 123.7, 124.6, 126.7, 126.8, 150.4, 157.0. MS (EI): $m / z=305\left[\mathrm{M}^{+}\right]$. Anal. Calcd for $\mathrm{C}_{19} \mathrm{H}_{15} \mathrm{NO}_{3}: \mathrm{C}, 74.74 ; \mathrm{H}, 4.95 ; \mathrm{N}$, 4.59\%. Found: C, 74.51; H, 4.91; N, 4.51\%.

$2.2 \mathrm{f}$ General procedure for the alkaline hydrolysis of 3-ethynyl-indole-2-carboxylic acid methyl ester $\mathbf{6 a - j}$ : To a solution of methanol $(3 \mathrm{~mL})$, ethanol $(1 \mathrm{~mL})$ and water $(2 \mathrm{~mL})$ was added 3-ethynyl-indole-2carboxylate $(500 \mathrm{mg})$ and stirred at room temperature for $5 \mathrm{~min}$. To this reaction mixture was added $\mathrm{NaOH}$ ( 1.5 equiv) and stirred at $75^{\circ} \mathrm{C}$ for $1 \mathrm{~h}$. After completion of the reaction as indicated by TLC, the reaction mixture was concentrated under reduced pressure. The residue was quenched with water $(10 \mathrm{~mL})$ and extracted with $\mathrm{Et}_{2} \mathrm{O}(3 \times 15 \mathrm{~mL})$ to remove the organic impurities. The aqueous extract was acidified $(\mathrm{pH}=1$ to 2$)$ with $10 \% \mathrm{HCl}$ and extracted with EtOAc $(3 \times 15 \mathrm{~mL})$. The combined organic extract was dried over anhydrous $\mathrm{Na}_{2} \mathrm{SO}_{4}$ and concentrated under reduced pressure to afford pure product $(\mathbf{6} \mathbf{a}-\mathbf{j})$, which was used for the next step.
$2.2 \mathrm{~g}$ General procedure for the synthesis of pyrano [3,4-b]-indol-1(9H)-ones 7a-j: To a mixture of 3ethynyl-indole-2-carboxylic acid $(1.0 \mathrm{mmol})$ in acetonitrile $(1 \mathrm{~mL})$ under $\mathrm{N}_{2}$ atmosphere was added $\mathrm{AuCl}_{3}$ ( $5 \mathrm{~mol} \%$ ) and refluxed for the specified time (table 1). After completion of the reaction as indicated by TLC, the reaction mixture was concentrated under reduced pressure and poured into water, and extracted with ethyl acetate $(3 \times 10 \mathrm{~mL})$. The organic layer was dried over anhydrous $\mathrm{Na}_{2} \mathrm{SO}_{4}$, filtered, concentrated, and purified by column chromatography on silica gel using petroleum ether/ethyl acetate to afford the pure product.

2.2g1 9-Methyl-3-phenylpyrano[3,4-b]indol-1(9H)-one (7a): $84 \%$ yield; Yellow solid; M.p. $168-170^{\circ} \mathrm{C}$; IR (KBr): 1711, 1471, 1222, 1063, $742 \mathrm{~cm}^{-1} \cdot{ }^{1} \mathrm{H}$ NMR $\left(500 \mathrm{MHz}, \mathrm{DMSO}-d_{6}\right.$, variable temperature): $\delta_{\mathrm{H}} 4.02$ $(\mathrm{s}, 3 \mathrm{H}) ; 7.22-7.23(\mathrm{~m}, 1 \mathrm{H})$; 7.36-7.56 (m, 5H); 7.817.85 (m, 3H); 8.02-8.04 (m, 1H). ${ }^{13} \mathrm{C}$ NMR $(125 \mathrm{MHz}$, DMSO- $d_{6}$, variable temperature): $\delta_{\mathrm{C}} 31.6,98.3,111.6$, $120.9,121.2,121.4,122.3,124.8,125.6,128.3,129.4$, 129.5, 132.6, 141.5, 151.6, 156.1. MS (EI): $m / z=275$ $\left[\mathrm{M}^{+}\right]$. Anal. Calcd for $\mathrm{C}_{18} \mathrm{H}_{13} \mathrm{NO}_{2}: \mathrm{C}, 78.53 ; \mathrm{H}, 4.76$; $\mathrm{N}, 5.09 \%$. Found: C, 78.69; H, 4.72; N, 5.03\%.

2.2g2 9-Ethyl-3-phenylpyrano[3,4-b]indol-1(9H)-one (7b): $85 \%$ yield; Orange solid; M.p. $70-75^{\circ} \mathrm{C}$; IR (KBr): 1712, 1469, 1220, 1061, $739 \mathrm{~cm}^{-1} .{ }^{1} \mathrm{H}$ NMR $\left(500 \mathrm{MHz}, \mathrm{CDCl}_{3}\right): \delta_{\mathrm{H}} 1.44(\mathrm{t}, 3 \mathrm{H}, J=7.6 \mathrm{~Hz}) ; 4.66$ $(\mathrm{q}, 2 \mathrm{H}, J=7.6 \mathrm{~Hz}) ; 7.24(\mathrm{t}, 1 \mathrm{H}, J=6.9 \mathrm{~Hz}) ; 7.29$ $(\mathrm{s}, 1 \mathrm{H}) ; 7.35(\mathrm{~d}, 1 \mathrm{H}, J=6.9 \mathrm{~Hz}) ; 7.41-7.43(\mathrm{~m}, 3 \mathrm{H})$; $7.49(\mathrm{t}, 1 \mathrm{H}, J=6.9 \mathrm{~Hz}) ; 7.85-7.89(\mathrm{~m}, 3 \mathrm{H}) .{ }^{13} \mathrm{C} \mathrm{NMR}$ $\left(125 \mathrm{MHz}, \mathrm{CDCl}_{3}\right): \delta_{\mathrm{C}} 15.9,39.6,97.1,110.7,120.4$, $120.9,121.4,121.7,124.9,125.9,127.9,128.8,129.1$, 132.6, 140.4, 152.4, 156.5. MS (EI): $m / z=289\left[\mathrm{M}^{+}\right]$.

Table 1. $\mathrm{AuCl}_{3}$ catalyzed synthesis of pyrano[3,4-b] indol-1 $(9 H)$-ones.

\begin{tabular}{lcccc}
\hline Entry & Substrate & Product $^{\mathrm{a}}$ & Time (min) & Yield (\%) $^{\mathrm{b}}$ \\
\hline 1 & $\mathbf{6 a}$ & $\mathbf{7 a}$ & 20 & 84 \\
2 & $\mathbf{6 b}$ & $\mathbf{7 b}$ & 20 & 85 \\
3 & $\mathbf{6 c}$ & $\mathbf{7 c}$ & 30 & 83 \\
4 & $\mathbf{6 d}$ & $\mathbf{7 d}$ & 05 & 92 \\
5 & $\mathbf{6 e}$ & $\mathbf{7 e}$ & 05 & 91 \\
6 & $\mathbf{6 f}$ & $\mathbf{7 f}$ & 15 & 88 \\
7 & $\mathbf{6 g}$ & $\mathbf{7 g}$ & 15 & 87 \\
8 & $\mathbf{6 h}$ & $\mathbf{7 h}$ & 20 & 79 \\
9 & $\mathbf{6 i}$ & $\mathbf{7 i}$ & 45 & 75 \\
10 & $\mathbf{6 j}$ & $\mathbf{7 j}$ & 40 & 77 \\
\hline
\end{tabular}

${ }^{\mathrm{a}}$ All the Products were characterized by IR, ${ }^{1} \mathrm{H}$ NMR, ${ }^{13} \mathrm{C}$ NMR and MS

${ }^{\mathrm{b}}$ Isolated yield after column chromatography 
Anal. Calcd for $\mathrm{C}_{19} \mathrm{H}_{15} \mathrm{NO}_{2}$ : C, 78.87; H, 5.23; N, 4.84\%. Found: C, 78.00; H, 4.28; N, 5.41\%.

2.2g3 9-Butyl-3-phenylpyrano[3,4-b]indol-1(9H)-one (7c): $83 \%$ yield; Colourless liquid; IR (neat): 2949, 1714, 1059, $743 \mathrm{~cm}^{-1} .{ }^{1} \mathrm{H}$ NMR $\left(500 \mathrm{MHz}, \mathrm{CDCl}_{3}\right)$ : $\delta_{\mathrm{H}} 0.94(\mathrm{t}, 3 \mathrm{H}, J=7.6 \mathrm{~Hz}) ; 1.36-1.42(\mathrm{~m}, 2 \mathrm{H}) ; 1.84$ $1.85(\mathrm{~m}, 2 \mathrm{H}) ; 4.68(\mathrm{t}, 2 \mathrm{H}, J=7.6 \mathrm{~Hz}) ; 7.27(\mathrm{t}, 1 \mathrm{H}$, $J=7.6 \mathrm{~Hz}) ; 7.36-7.39(\mathrm{~m}, 2 \mathrm{H}) ; 7.43-7.53(\mathrm{~m}, 4 \mathrm{H})$; 7.89-7.94 $(\mathrm{m}, 3 \mathrm{H}) \cdot{ }^{13} \mathrm{C}$ NMR $\left(125 \mathrm{MHz}, \mathrm{CDCl}_{3}\right): \delta_{\mathrm{C}}$ 14.2, 22.7, 31.7, 44.6, 97.1, 111.0, 120.9, 121.4, 121.7, $124.9,125.9,127.8,128.8,129.1,132.7,140.9,152.5$, 156.6. MS (EI): $m / z=317\left[\mathrm{M}^{+}\right]$. Anal. Calcd for $\mathrm{C}_{21} \mathrm{H}_{19} \mathrm{NO}_{2}$ : C, 79.47; H, 6.03; N, 4.41\%. Found: C, $79.69 ; \mathrm{H}, 6.20 ; \mathrm{N}, 4.35 \%$.

2.2g4 6-Methoxy-9-methyl-3-phenylpyrano[3,4-b]indol1(9H)-one (7d): $92 \%$ yield; Brown solid; M.p. 138$140^{\circ} \mathrm{C}$; IR (KBr): $3254,2550,1666,1569,1365,1057$, $658 \mathrm{~cm}^{-1}$. ${ }^{1} \mathrm{H}$ NMR $\left(500 \mathrm{MHz}\right.$, Acetone- $d_{6}$, variable temperature): $\delta_{\mathrm{H}} 3.86(\mathrm{~s}, 3 \mathrm{H}) ; 4.14(\mathrm{~s}, 3 \mathrm{H}) ; 7.18(\mathrm{~s}, 1 \mathrm{H})$; 7.38-7.55 (m, 5H); $7.74(\mathrm{~s}, 1 \mathrm{H}) ; 7.89-7.91(\mathrm{~m}, 2 \mathrm{H})$. ${ }^{13} \mathrm{C}$ NMR $\left(125 \mathrm{MHz}\right.$, Acetone- $d_{6}$, variable temperature): $\delta_{\mathrm{C}} 30.7,55.1,97.5,101.7,110.9,111.9,119.2$, 121.2, 121.6, 124.4, 124.7, 128.7, 128.8, 128.9, 136.9, 151.3, 155.2. MS (EI): $m / z=305\left[\mathrm{M}^{+}\right]$. Anal. Calcd for $\mathrm{C}_{19} \mathrm{H}_{15} \mathrm{NO}_{3}$ : C, 74.74; $\mathrm{H}, 4.95 ; \mathrm{N}, 4.59 \%$. Found: C, 74.99; H, 4.90; N, 4.51\%.

\section{2g5 9-Ethyl-6-methoxy-3-phenylpyrano[3,4-b]indol-} 1(9H)-one (7e): $91 \%$ yield; Brown solid; M.p. 118$120^{\circ} \mathrm{C}$; IR (KBr): 3447, 1711, 1460, 1237, 1056, $759 \mathrm{~cm}^{-1}$. ${ }^{1} \mathrm{H}$ NMR $\left(500 \mathrm{MHz}\right.$, Acetone- $\left.d_{6}\right): \delta_{\mathrm{H}} 1.37$ $(\mathrm{t}, 3 \mathrm{H}, J=6.9 \mathrm{~Hz}) ; 3.86(\mathrm{~s}, 3 \mathrm{H}) ; 4.70(\mathrm{q}, 2 \mathrm{H}, J=$ $7.6 \mathrm{~Hz}) ; 7.17\left(\mathrm{dd}, 1 \mathrm{H}, J_{1}=2.3 \mathrm{~Hz}, J_{2}=6.9 \mathrm{~Hz}\right) ; 7.37$ $(\mathrm{t}, 1 \mathrm{H}, J=7.6 \mathrm{~Hz}) ; 7.46(\mathrm{t}, 2 \mathrm{H}, J=7.6 \mathrm{~Hz}) ; 7.56-7.58$ $(\mathrm{m}, 2 \mathrm{H}) ; 7.76(\mathrm{~s}, 1 \mathrm{H}) ; 7.89(\mathrm{~d}, 2 \mathrm{H}, J=6.9 \mathrm{~Hz}) .{ }^{13} \mathrm{C}$ NMR $\left(125 \mathrm{MHz}\right.$, Acetone- $\left.d_{6}\right): \delta_{\mathrm{C}} 15.4,39.4,55.1$, 97.5, 101.9, 111.9, 119.3, 120.4, 121.9, 124.5, 125.1, $128.8,128.9,133.0,135.8,151.4,155.1,155.6 . \mathrm{MS}$ (EI): $m / z=319\left[\mathrm{M}^{+}\right]$. Anal. Calcd for $\mathrm{C}_{20} \mathrm{H}_{17} \mathrm{NO}_{3}: \mathrm{C}$, 75.22; H, 5.37; N, 4.39\%. Found: C, 75.39; H, 5.33; N, $4.32 \%$.

2.2g6 9-Butyl-6-methoxy-3-phenylpyrano[3,4-b]indol-1 (9H)-one (7f): $88 \%$ yield; Yellow liquid; IR (neat): 2928, 1711, 1501, 1239, 1060, $762 \mathrm{~cm}^{-1}$. ${ }^{1} \mathrm{H}$ NMR $\left(500 \mathrm{MHz}, \mathrm{CDCl}_{3}\right): \delta_{\mathrm{H}} 0.92(\mathrm{t}, 3 \mathrm{H}, J=7.6 \mathrm{~Hz}) ; 1.34$ $1.38(\mathrm{~m}, 2 \mathrm{H}) ; 1.81-1.84(\mathrm{~m}, 2 \mathrm{H}) ; 3.91(\mathrm{~s}, 3 \mathrm{H}) ; 4.64$ $(\mathrm{t}, 2 \mathrm{H}, J=6.8 \mathrm{~Hz}) ; 7.17\left(\mathrm{dd}, 1 \mathrm{H}, J_{1}=11.45 ; J_{2}=\right.$ $2.3 \mathrm{~Hz}) ; 7.29(\mathrm{~d}, 1 \mathrm{H}, J=2.3 \mathrm{~Hz}) ; 7.33(\mathrm{~s}, 1 \mathrm{H}) ; 7.36$ $7.39(\mathrm{~m}, 2 \mathrm{H}) ; 7.44(\mathrm{t}, 2 \mathrm{H}, J=7.6 \mathrm{~Hz}) ; 7.88(\mathrm{~d}, 2 \mathrm{H}$, $J=7.6 \mathrm{~Hz}) \cdot{ }^{13} \mathrm{C} \mathrm{NMR}\left(125 \mathrm{MHz}, \mathrm{CDCl}_{3}\right): \delta_{\mathrm{C}} 13.9$,
20.1, 33.0, 44.7, 55.9, 97.2, 101.6, 112.0, 119.4, 121.1, $121.5,124.8,125.1,128.8,128.9,132.7,136.3,151.8$, 154.8, 156.6. MS (EI): $m / z=347\left[\mathrm{M}^{+}\right]$. Anal. Calcd for $\mathrm{C}_{22} \mathrm{H}_{21} \mathrm{NO}_{3}$ : C, 76.06; H, 6.09; N, 4.03\%. Found: C, $75.89 ; \mathrm{H}, 6.14 ; \mathrm{N}, 4.13 \%$.

2.2g7 9-Benzyl-6-methoxy-3-phenylpyrano[3,4-b]indol1(9H)-one (7g): $87 \%$ yield; Yellow solid; M.p. 186$188^{\circ} \mathrm{C}$; IR (KBr): 3446, 1694, 1233, 1069, 764, $693 \mathrm{~cm}^{-1}$. ${ }^{1} \mathrm{H}$ NMR $\left(500 \mathrm{MHz}, \mathrm{CDCl}_{3}\right): \delta_{\mathrm{H}} 3.89(\mathrm{~s}$, $3 \mathrm{H}) ; 5.89$ (s, 2H); $7.13(\mathrm{~d}, 1 \mathrm{H}, J=7.6 \mathrm{~Hz}) ; 7.21-$ $7.26(\mathrm{~m}, 5 \mathrm{H}) ; 7.30(\mathrm{~s}, 1 \mathrm{H}) ; 7.33-7.39(\mathrm{~m}, 3 \mathrm{H}) ; 7.45$ $(\mathrm{t}, 2 \mathrm{H}, J=7.6 \mathrm{~Hz}) ; 7.89(\mathrm{~d}, 2 \mathrm{H}, J=7.6 \mathrm{~Hz}) .{ }^{13} \mathrm{C}$ NMR $\left(125 \mathrm{MHz}, \mathrm{CDCl}_{3}\right): \delta_{\mathrm{C}} 48.2,55.9,97.2,101.8$, $112.5,119.6,121.9,124.9,125.7,127.1,127.6,128.8$, 128.9, 129.1, 132.8, 136.4, 137.5, 152.2, 155.1, 156.8, 163.6. MS (EI): $m / z=381\left[\mathrm{M}^{+}\right]$. Anal. Calcd for $\mathrm{C}_{25} \mathrm{H}_{19} \mathrm{NO}_{3}$ : C, 78.72; H, 5.02; N, 3.67\%. Found: C, $78.89 ; \mathrm{H}, 4.98 ; \mathrm{N}, 3.60 \%$.

2.2g8 3-Butylpyrano[3,4-b]indol-1(9H)-one (7h): 79\% yield; Colourless solid; M.p. $158-160^{\circ} \mathrm{C}$; IR (KBr): 3261, 1688, 1621, $748 \mathrm{~cm}^{-1}$. ${ }^{1} \mathrm{H}$ NMR $(500 \mathrm{MHz}$, $\left.\mathrm{CDCl}_{3}+\mathrm{DMSO}-d_{6}\right): \delta_{\mathrm{H}} 0.86(\mathrm{t}, 3 \mathrm{H}, J=6.9 \mathrm{~Hz})$; $1.31-1.33(\mathrm{~m}, 2 \mathrm{H}) ; 1.60-1.63(\mathrm{~m}, 2 \mathrm{H}) ; 2.54(\mathrm{t}, 2 \mathrm{H}$, $J=6.9 \mathrm{~Hz}) ; 6.62(\mathrm{~s}, 1 \mathrm{H}) ; 7.11(\mathrm{t}, 1 \mathrm{H}, J=7.6 \mathrm{~Hz}) ; 7.34$ $(\mathrm{t}, 1 \mathrm{H}, J=7.6 \mathrm{~Hz}) ; 7.50(\mathrm{~d}, 1 \mathrm{H}, J=8.4 \mathrm{~Hz}) ; 7.73(\mathrm{~d}$, $1 \mathrm{H}, J=8.4 \mathrm{~Hz}) ; 11.17$ (s, $1 \mathrm{H}) .{ }^{13} \mathrm{C} \mathrm{NMR}(125 \mathrm{MHz}$, $\left.\mathrm{CDCl}_{3}+\mathrm{DMSO}-d_{6}\right): \delta_{\mathrm{C}} 13.8,22.1,29.6,33.3,98.5$, 113.2, 120.5, 120.6, 121.3, 121.5, 126.0, 127.6, 140.3, 156.7, 158.3. MS (EI): $m / z=241\left[\mathrm{M}^{+}\right]$. Anal. Calcd for $\mathrm{C}_{15} \mathrm{H}_{15} \mathrm{NO}_{2}: \mathrm{C}, 74.67 ; \mathrm{H}, 6.27 ; \mathrm{N}, 5.81 \%$. Found: $\mathrm{C}$, $74.89 ; \mathrm{H}, 6.24 ; \mathrm{N}, 5.75 \%$.

2.2g9 3-Phenylpyrano[3,4-b]indol-1(9H)-one (7i): 75\% yield; Yellow solid; M.p. $171-173^{\circ} \mathrm{C}$; IR (KBr): 3401 , 2921, 1686, $742 \mathrm{~cm}^{-1} .{ }^{1} \mathrm{H}$ NMR $\left(500 \mathrm{MHz}, \mathrm{CDCl}_{3}+\right.$ DMSO- $\left.d_{6}\right): \delta_{\mathrm{H}} 7.13(\mathrm{t}, 1 \mathrm{H}, J=6.8 \mathrm{~Hz}) ; 7.17-7.19(\mathrm{~m}$, $1 \mathrm{H}) ; 7.27(\mathrm{~d}, 1 \mathrm{H}, J=6.8 \mathrm{~Hz}) ; 7.34-7.37(\mathrm{~m}, 3 \mathrm{H})$; $7.39(\mathrm{~s}, 1 \mathrm{H}) ; 7.45-7.50(\mathrm{~m}, 1 \mathrm{H}) ; 7.79(\mathrm{~d}, 1 \mathrm{H}, J=$ $7.6 \mathrm{~Hz}) ; 7.84(\mathrm{~d}, 1 \mathrm{H}, J=7.6 \mathrm{~Hz}) ; 11.94(\mathrm{~s}, 1 \mathrm{H}) .{ }^{13} \mathrm{C}$ NMR $\left(125 \mathrm{MHz}, \mathrm{CDCl}_{3}+\mathrm{DMSO}-d_{6}\right): \delta_{\mathrm{C}} 97.7,113.4$, $120.8,121.4,121.9,124.3,124.8,125.6,127.7,128.9$, 129.0, 132.8, 140.6, 151.9, 157.0. MS (EI): $m / z=261$ $\left[\mathrm{M}^{+}\right]$. Anal. Calcd for $\mathrm{C}_{17} \mathrm{H}_{11} \mathrm{NO}_{2}$ : C, 78.15; H, 4.24; N, 5.36\%. Found: C, 78.39; H, 4.19; N, 5.26\%.

2.2g10 6-Methoxy-3-phenylpyrano[3,4-b]indol-1(9H)one (7j): $77 \%$ yield; Brown solid; M.p. $232-234^{\circ} \mathrm{C}$; IR (KBr): 3223, 1707, 1480, 1219, $1080 \mathrm{~cm}^{-1} \cdot{ }^{1} \mathrm{H}$ NMR $\left(500 \mathrm{MHz}, \mathrm{CDCl}_{3}+\mathrm{DMSO}-d_{6}\right): \delta_{\mathrm{H}} 3.78(\mathrm{~s}, 3 \mathrm{H})$; $6.98(\mathrm{~d}, 1 \mathrm{H}, J=6.9 \mathrm{~Hz}) ; 7.23-7.27(\mathrm{~m}, 2 \mathrm{H}) ; 7.32-7.38$ 
$(\mathrm{m}, 4 \mathrm{H}) ; 7.77(\mathrm{~d}, 2 \mathrm{H}, J=7.6 \mathrm{~Hz}) ; 11.86(\mathrm{~s}, 1 \mathrm{H}) .{ }^{13} \mathrm{C}$ NMR $\left(125 \mathrm{MHz}, \mathrm{CDCl}_{3}+\right.$ DMSO- $\left.d_{6}\right): \delta_{\mathrm{C}} 55.7,97.8$, $101.4,114.3,119.2,121.7,122.2,124.7,125.0,128.9$ ( 2 carbon), 132.9, 135.9, 151.3, 154.7, 156.9. MS (EI): $m / z=291\left[\mathrm{M}^{+}\right]$. Anal. Calcd for $\mathrm{C}_{18} \mathrm{H}_{13} \mathrm{NO}_{3}: \mathrm{C}$, 74.22; H, 4.50; N, 4.81\%. Found: C, 74.49; H, 4.44; N, $4.73 \%$.

2.2h Experimental procedure for the synthesis of 2bromo-indole-3-carbaldehyde 9a: To a solution of anhydrous DMF $(27.5 \mathrm{~g})$ in anhydrous 1,2-dichloroethane $(100 \mathrm{~mL})$ was added $\mathrm{POBr}_{3}(26.8 \mathrm{~g}, 0.0937 \mathrm{~mol})$ dropwise at $0^{\circ} \mathrm{C}$ under argon atmosphere. The resulting mixture was allowed to stir for $30 \mathrm{~min}$ followed by addition with a solution of 2-oxindole $(5.0 \mathrm{~g}, 0.0375 \mathrm{~mol})$ in dichloroethane $(100 \mathrm{~mL})$. The resulting mixture was stirred at room temperature for $24 \mathrm{~h}$ and quenched with ice-cold solution of excess $\mathrm{NaOAc} \cdot 3 \mathrm{H}_{2} \mathrm{O}$. The product was extracted with dichloroethane $(3 \times 100 \mathrm{~mL})$, dried over anhydrous sodium sulphate and evaporated under reduced pressure. The crude product was further purified by recrystallization using $95 \% \mathrm{EtOH}$ to afford $5.9 \mathrm{~g}$ ( $82 \%$ yield) of analytically pure compound $\mathbf{9 a}$ as a beige solid; M.p. 220 to $222^{\circ} \mathrm{C} .{ }^{1} \mathrm{H}$ NMR $(500 \mathrm{MHz}$, DMSO- $\left.d_{6}\right): \delta_{\mathrm{H}} 7.00-7.05(\mathrm{~m}, 2 \mathrm{H}), 7.21(\mathrm{~d}, 1 \mathrm{H}, J=$ $7.6 \mathrm{~Hz}), 8.02(\mathrm{~d}, 1 \mathrm{H}, J=7.6 \mathrm{~Hz}), 9.80(\mathrm{~s}, 1 \mathrm{H}), 12.21$ (s, 1H).

$2.2 \mathrm{i}$ Experimental procedure for the oxidative esterification of $9 a$ to 10a: To a solution of 2-bromo-indole3 -carbaldehyde $(5.0 \mathrm{~g}, 0.0223 \mathrm{~mol})$ in dry $\mathrm{MeOH}$ $(100 \mathrm{~mL})$ was added oxone $\mathbb{R}(3.56 \mathrm{~g}, 0.0234 \mathrm{~mol})$ portion wise and stirred at room temperature. After $3 \mathrm{~h}$, the reaction mixture was quenched with water $(100 \mathrm{~mL})$ and extracted with dichloromethane $(3 \times 100 \mathrm{~mL})$. The organic layer was dried over anhydrous sodium sulphate and concentrated under reduced pressure to afford the ester which was used for the next step without further purification.

$2.2 \mathrm{j}$ General procedure for the $N$-alkylation of 2bromo-indole-3-carboxylic acid methyl ester 11a and 11b: To a mixture of $\mathrm{NaH}$ (2.0 equiv) in DMF ( $3 \mathrm{~mL})$ kept at $0^{\circ} \mathrm{C}$ at $\mathrm{N}_{2}$ atmosphere was added a solution of 2-bromo-indole-3-carboxylic acid methyl ester 10a (1.0 equiv) in DMF ( $2 \mathrm{~mL}$ ) and stirred for $15 \mathrm{~min}$. To this mixture was added the corresponding alkyl halide (1.2 equiv) and stirred for $3 \mathrm{~h}$ at $0^{\circ} \mathrm{C}$ to room temperature. After completion of the reaction as indicated by TLC, the reaction mixture was quenched with water and extracted with EtOAc $(3 \times 10 \mathrm{~mL})$. The organic layer was dried over anhydrous $\mathrm{Na}_{2} \mathrm{SO}_{4}$, filtered, concentrated and purified by column chromatography on silica gel using petroleum ether/EtOAc to afford the pure product.

2.2j1 Methyl 2-bromo-1-methyl-1H-indole-3-carboxylate (11a): $92 \%$ yield; colourless liquid; IR (neat): 2919, 2355, 1709, 1457, 1245, 1108, $751 \mathrm{~cm}^{-1} .{ }^{1} \mathrm{H}$ NMR $\left(500 \mathrm{MHz}, \mathrm{CDCl}_{3} 4\right): \delta_{\mathrm{H}} 3.75(\mathrm{~s}, 3 \mathrm{H}) ; 4.01(\mathrm{~s}$, $3 \mathrm{H}) ; 7.42(\mathrm{~d}, 1 \mathrm{H}, J=7.6 \mathrm{~Hz}) ; 7.55(\mathrm{t}, 1 \mathrm{H}, J=8.4 \mathrm{~Hz})$; $7.67(\mathrm{t}, 1 \mathrm{H}, J=8.4 \mathrm{~Hz}) ; 8.21(\mathrm{~d}, 1 \mathrm{H}, J=7.6 \mathrm{~Hz}) .{ }^{13} \mathrm{C}$ NMR $\left(125 \mathrm{MHz}, \mathrm{CDCl}_{3}\right): \delta_{\mathrm{C}} 33.4,51.9,109.9,110.3$, $111.1,120.5,121.8,122.2,128.9,138.8,164.1$. MS (EI): $m / z=267\left[\mathrm{M}^{+}\right], 269\left[\mathrm{M}^{+2}\right]$

2.2j2 Methyl 2-bromo-1-ethyl-1H-indole-3-carboxylate (11b): $89 \%$ yield; colourless solid; M.p. $73-75^{\circ} \mathrm{C}$; IR (KBr): 2925, 1705, 1459, 1218, 1009, $741 \mathrm{~cm}^{-1} \cdot{ }^{1} \mathrm{H}$ NMR $\left(500 \mathrm{MHz}, \mathrm{CDCl}_{3}\right): \delta_{\mathrm{H}} 1.42(\mathrm{t}, 3 \mathrm{H}, J=7.6 \mathrm{~Hz})$; $3.95(\mathrm{~s}, 3 \mathrm{H}) ; 4.32(\mathrm{q}, 2 \mathrm{H}, J=7.6 \mathrm{~Hz}) ; 7.45(\mathrm{~d}, 1 \mathrm{H}, J=$ $7.6 \mathrm{~Hz}) ; 7.95(\mathrm{t}, 1 \mathrm{H}, J=8.4 \mathrm{~Hz}) ; 8.03(\mathrm{t}, 1 \mathrm{H}, J=$ $8.4 \mathrm{~Hz}) ; 8.44(\mathrm{~d}, 1 \mathrm{H}, J=7.66 \mathrm{~Hz}) .{ }^{13} \mathrm{C} \mathrm{NMR}(125 \mathrm{MHz}$, $\left.\mathrm{CDCl}_{3}\right): \delta_{\mathrm{C}} 14.6,43.0,52.6,110.6,111.2,112.1,120.0$, 122.8, 123.1, 132.1, 138.6, 166.7. MS(EI): $m / z=281$ $\left[\mathrm{M}^{+}\right], 283\left[\mathrm{M}^{+2}\right]$

2.2k General procedure for the N-alkylation of 3iodo-indole-2-carboxylic acid methyl ester $11 \mathrm{c}$ and 11d: To a mixture of $\mathrm{KOH}$ (3.0 equiv) in DMSO $(3 \mathrm{~mL})$ kept at $0^{\circ} \mathrm{C}$ was added, 2-bromo-indole-2carboxylic acid methyl ester 10a (1.0 equiv) and stirred for $30 \mathrm{~min}$. To this mixture was added the corresponding alkyl halide (5.0 equiv) and stirred for $6 \mathrm{~h}$ at $0^{\circ} \mathrm{C}$ to room temperature. After completion of the reaction as indicated by TLC, the reaction mixture was quenched with water and extracted with EtOAc $(3 \times 15 \mathrm{~mL})$. The organic layer was dried over anhydrous $\mathrm{Na}_{2} \mathrm{SO}_{4}$, filtered, concentrated and purified by column chromatography on silica gel using petroleum ether/EtOAc to afford the pure product.

2.2k1 Methyl 2-bromo-1-butyl-1H-indole-3-carboxylate (11c): $75 \%$ yield; Colourless solid; M.p. 113$115^{\circ} \mathrm{C}$; IR (KBr): 2959, 1715, 1460, 1358, 1256, 1202 , $1144,746 \mathrm{~cm}^{-1} .{ }^{1} \mathrm{H}$ NMR $\left(500 \mathrm{MHz}, \mathrm{CDCl}_{3}\right): \delta_{\mathrm{H}} 0.88$ $(\mathrm{t}, 3 \mathrm{H}, J=7.6 \mathrm{~Hz}) ; 1.29-1.35(\mathrm{~m}, 2 \mathrm{H}) ; 1.65-1.71(\mathrm{~m}$, $2 \mathrm{H}) ; 3.97(\mathrm{~s}, 3 \mathrm{H}) ; 4.21(\mathrm{t}, 2 \mathrm{H}) ; 7.34(\mathrm{~d}, 1 \mathrm{H}, J=8.1 \mathrm{~Hz})$; $7.75(\mathrm{t}, 1 \mathrm{H}, J=8.4 \mathrm{~Hz}) ; 8.01(\mathrm{t}, 1 \mathrm{H}, J=8.4 \mathrm{~Hz}) ; 8.38$ $(\mathrm{d}, 1 \mathrm{H}, J=8.1 \mathrm{~Hz}) \cdot{ }^{13} \mathrm{C}$ NMR $\left(125 \mathrm{MHz}, \mathrm{CDCl}_{3}\right): \delta_{\mathrm{C}}$ 13.5, 20.3, 33.3, 52.8, 53.7, 110.1, 110.9, 111.2, 119.7, 121.9, 122.6, 129.6, 138.6, 166.3. MS(EI): $m / z=309$ $\left[\mathrm{M}^{+}\right], 311\left[\mathrm{M}^{+2}\right]$ 
2.2k2 Methyl 1-benzyl-2-bromo-1H-indole-3-carboxylate (11d): $80 \%$ yield; Colourless solid; M.p. 153$155^{\circ} \mathrm{C}$; IR (KBr): 2949, 1716, 1455, 1255, 1209, $767 \mathrm{~cm}^{-1} .{ }^{1} \mathrm{H} \mathrm{NMR}\left(500 \mathrm{MHz}, \mathrm{CDCl}_{3}\right): \delta_{\mathrm{H}} 3.88(\mathrm{~s}, 3 \mathrm{H})$; $5.67(\mathrm{~s}, 2 \mathrm{H}) ; 7.27-7.34(\mathrm{~m}, 2 \mathrm{H}) ; 7.39-7.42(\mathrm{~m}, 2 \mathrm{H})$; $7.77(\mathrm{~d}, 1 \mathrm{H}, J=8.2 \mathrm{~Hz}) ; 7.86-7.94(\mathrm{~m}, 2 \mathrm{H}) ; 8.19(\mathrm{~d}$, $1 \mathrm{H}, J=8.2 \mathrm{~Hz}) .{ }^{13} \mathrm{C} \mathrm{NMR}\left(125 \mathrm{MHz}, \mathrm{CDCl}_{3}\right): \delta_{\mathrm{C}} 51.3$, 55.9, 110.1, 110.9, 111.4, 120.1, 121.8, 122.9, 126.2, $127.2,129.0,134.3,137.9,138.2,166.8 . \quad \mathrm{MS}(\mathrm{EI})$ : $m / z=343\left[\mathrm{M}^{+}\right], 345\left[\mathrm{M}^{+2}\right]$

2.21 General procedure for the synthesis of 2-ethynylindole-3-carboxylic acid methyl ester 12a-j: To a mixture of 2-bromo-indole-3-carboxylic acid methyl ester (1.0 mmoL), $\mathrm{Pd}\left(\mathrm{Ph}_{3} \mathrm{P}\right)_{4}(5.0 \mathrm{~mol} \%)$ and $\mathrm{CuI}(5.0 \mathrm{~mol} \%)$ under $\mathrm{N}_{2}$ atmosphere was added triethylamine $(5 \mathrm{~mL})$ and stirred for $30 \mathrm{~min}$. To this reaction mixture was added the appropriate terminal alkyne $(1.1 \mathrm{mmol})$ and stirred at room temperature for $10 \mathrm{~h}$. After completion of the reaction as indicated by TLC, the reaction mixture was quenched with water $(50 \mathrm{~mL})$ and extracted with EtOAc $(3 \times 15 \mathrm{~mL})$. The organic layer was dried over anhydrous $\mathrm{Na}_{2} \mathrm{SO}_{4}$, filtered, concentrated and purified by column chromatography on silica gel using petroleum ether/EtOAc to afford the pure product.

2.211 Methyl 1-methyl-2-(phenylethynyl)-1H-indole3-carboxylate (12a): $85 \%$ yield; Yellow solid; M.p. 89-91 ${ }^{\circ} \mathrm{C}$; IR (KBr): 3381, 2382, 1711, 1475, 1265 , $1101,752 \mathrm{~cm}^{-1} .{ }^{1} \mathrm{H}$ NMR $\left(500 \mathrm{MHz}, \mathrm{CDCl}_{3}\right): \delta_{\mathrm{H}} 3.87$ $(\mathrm{s}, 3 \mathrm{H}) ; 4.01(\mathrm{~s}, 3 \mathrm{H}) ; 7.36-7.59(\mathrm{~m}, 6 \mathrm{H}) ; 7.67(\mathrm{t}, 1 \mathrm{H}$, $J=7.6 \mathrm{~Hz}) ; 7.82(\mathrm{t}, 1 \mathrm{H}, J=7.6 \mathrm{~Hz}) ; 8.14(\mathrm{~d}, 1 \mathrm{H}$, $J=8.1 \mathrm{~Hz}) \cdot{ }^{13} \mathrm{C}$ NMR $\left(500 \mathrm{MHz}, \mathrm{CDCl}_{3}\right): \delta_{\mathrm{C}} 37.0$, $52.1,88.1,90.2,110.1,111.9,122.4,122.9,124.1$, $125.3,126.6,126.8,129.5,130.3,132.1,136.8$. 165.5. $\mathrm{MS}(\mathrm{EI}): m / z=289\left[\mathrm{M}^{+}\right]$

2.212 Methyl 1-ethyl-2-(phenylethynyl)-1H-indole-3carboxylate $(\mathbf{1 2 b})$ : $87 \%$ yield; Yellow solid; M.p. 103-105 ${ }^{\circ}$; IR (KBr): 3398, 2975, 1709, 1467, 1250, 1126, $745 \mathrm{~cm}^{-1} .{ }^{1} \mathrm{H}$ NMR $\left(500 \mathrm{MHz}, \mathrm{CDCl}_{3}\right): \delta_{\mathrm{H}} 1.27$ $(\mathrm{t}, 3 \mathrm{H}, J=7.7 \mathrm{~Hz}) ; 3.92(\mathrm{~s}, 3 \mathrm{H}) ; 4.19(\mathrm{q}, 2 \mathrm{H}, J=$ $7.7 \mathrm{~Hz}) ; 7.38-7.48(\mathrm{~m}, 4 \mathrm{H}) ; 7.59(\mathrm{~d}, 2 \mathrm{H}, J=6.9 \mathrm{~Hz})$; $7.71(\mathrm{t}, 1 \mathrm{H}, J=7.2 \mathrm{~Hz}) ; 7.86(\mathrm{t}, 1 \mathrm{H}, J=7.2 \mathrm{~Hz}) ; 8.04$ $(\mathrm{d}, 1 \mathrm{H}, J=7.6 \mathrm{~Hz}) .{ }^{13} \mathrm{C} \mathrm{NMR}\left(500 \mathrm{MHz}, \mathrm{CDCl}_{3}\right): \delta_{\mathrm{C}}$ 14.3, 42.5, 51.6, 86.8, 90.4, 109.7, 110.4, 110.9, 119.7, $121.8,122.4,126.9,137.1,165.7 . \mathrm{MS}(\mathrm{EI}): m / z=303$ $\left[\mathrm{M}^{+}\right]$

2.213 Methyl 1-butyl-2-(phenylethynyl)-1H-indole-3carboxylate (12c): $81 \%$ yield; Pale yellow solid; M.p. 114-116 ${ }^{\circ} \mathrm{C}$; IR (KBr): 3367, 2925, 1710, 1465, 1365, 1240, 1210, 1129, $763 \mathrm{~cm}^{-1}$. ${ }^{1} \mathrm{H}$ NMR $(500 \mathrm{MHz}$,
$\left.\mathrm{CDCl}_{3}\right): \delta_{\mathrm{H}} 0.91(\mathrm{t}, 3 \mathrm{H}, J=7.6 \mathrm{~Hz}) ; 1.32-1.37(\mathrm{~m}$, $2 \mathrm{H})$; $1.69-1.75$ (m, 2H); 3.95 (s, 3H); 4.19 (t, 2H, $J=$ $6.8 \mathrm{~Hz}) ; 7.35-7.45(\mathrm{~m}, 4 \mathrm{H}) ; 7.55(\mathrm{~d}, 2 \mathrm{H}, J=6.9 \mathrm{~Hz})$; $7.77(\mathrm{t}, 1 \mathrm{H}, J=7.8 \mathrm{~Hz}) ; 7.92(\mathrm{t}, 1 \mathrm{H}, J=7.8 \mathrm{~Hz}) ; 8.03$ $(\mathrm{d}, 1 \mathrm{H}, J=7.1 \mathrm{~Hz}) .{ }^{13} \mathrm{C}$ NMR $\left(500 \mathrm{MHz}, \mathrm{CDCl}_{3}\right): \delta_{\mathrm{C}}$ 13.5, 20.4, 32.4, 52.1, 52.3, 86.6, 90.1, 109.4, 110.5, $111.2,119.5,121.3,121.9,122.4,127.1,128.3,128.5$, 133.3, 138.1, 165.4. $\mathrm{MS}(\mathrm{EI}): m / z=331\left[\mathrm{M}^{+}\right]$

2.214 Methyl 1-benzyl-2-(phenylethynyl)-1H-indole3-carboxylate (12d): $91 \%$ yield; Yellow solid; M.p. 168-170 ${ }^{\circ}$; IR (KBr): 3356, 2948, 1701, 1245, 1211, $713 \mathrm{~cm}^{-1} .{ }^{1} \mathrm{H} \mathrm{NMR}\left(500 \mathrm{MHz}, \mathrm{CDCl}_{3}\right): \delta_{\mathrm{H}} 3.99(\mathrm{~s}, 3 \mathrm{H})$; $5.71(\mathrm{~s}, 2 \mathrm{H}) ; 7.21-7.34(\mathrm{~m}, 5 \mathrm{H}) ; 7.43-7.51(\mathrm{~m}, 3 \mathrm{H})$; $7.58-7.73(\mathrm{~m}, 5 \mathrm{H}) ; 7.98(\mathrm{~d}, 1 \mathrm{H}, J=6.9 \mathrm{~Hz}) .{ }^{13} \mathrm{C} \mathrm{NMR}$ $\left(500 \mathrm{MHz}, \mathrm{CDCl}_{3}\right): \delta_{\mathrm{C}} 51.9,56.0,87.2,90.1,109.5$, $110.1,110.4,120.0,121.4,122.1,122.5,125.5,126.5$, 127.4, 128.3, 128.5, 128.7, 132.6, 136.9, 137.2, 166.6. $\mathrm{MS}(\mathrm{EI}): m / z=365\left[\mathrm{M}^{+}\right]$

2.215 Methyl 2-(hex-1-yn-1-yl)-1-methyl-1H-indole3-carboxylate (12e): $74 \%$ yield; Colourless solid; M.p. $103-105^{\circ} \mathrm{C}$; IR (KBr): $3315,1695,1455,1211$, $746 \mathrm{~cm}^{-1} .{ }^{1} \mathrm{H}$ NMR $\left(500 \mathrm{MHz}, \mathrm{CDCl}_{3}\right): \delta_{\mathrm{H}} 0.88(\mathrm{t}, 3 \mathrm{H}$, $J=7.6 \mathrm{~Hz}) ; 1.31-1.35$ (m, 2H); 1.41-1.44 (m, 2H); $3.72(\mathrm{~s}, 3 \mathrm{H}) ; 4.08$ (s, 3H); $7.28(\mathrm{~d}, 1 \mathrm{H}, J=8.4 \mathrm{~Hz})$; $7.57(\mathrm{t}, 1 \mathrm{H}, J=7.2 \mathrm{~Hz}) ; 7.71(\mathrm{t}, 1 \mathrm{H}, J=8.4 \mathrm{~Hz}) ; 7.89$ $(\mathrm{d}, 1 \mathrm{H}, J=7.1 \mathrm{~Hz}) .{ }^{13} \mathrm{C} \mathrm{NMR}\left(500 \mathrm{MHz}, \mathrm{CDCl}_{3}\right)$ : $\delta_{\mathrm{C}} 13.0,21.4,22.1,30.5,36.3,51.4,76.5,77.2,109.8$, $110.7,112.3,119.5,120.4,122.1,127.9,136.7,167.1$. $\mathrm{MS}(\mathrm{EI}): m / z=269\left[\mathrm{M}^{+}\right]$

2.216 Methyl 1-ethyl-2-(hex-1-yn-1-yl)-1H-indole-3carboxylate (12f): $77 \%$ yield; Colourless solid; M.p. $109-111^{\circ} \mathrm{C}$; IR (KBr): 3325, 1702, 1457, 1218, 739 $\mathrm{cm}^{-1} \cdot{ }^{1} \mathrm{H} \mathrm{NMR}\left(500 \mathrm{MHz}, \mathrm{CDCl}_{3}\right): \delta_{\mathrm{H}} 0.91(\mathrm{t}, 3 \mathrm{H}$, $J=7.1 \mathrm{~Hz}) ; 1.31(\mathrm{t}, 3 \mathrm{H}, J=7.6 \mathrm{~Hz}) ; 1.37-1.41(\mathrm{~m}$, $2 \mathrm{H}) ; 1.44-1.47$ (m, 2H); $2.42(\mathrm{t}, 2 \mathrm{H}, J=6.9 \mathrm{~Hz}) ; 4.01$ $(\mathrm{s}, 3 \mathrm{H}) ; 4.25(\mathrm{q}, 2 \mathrm{H}, J=7.6 \mathrm{~Hz}) ; 7.34(\mathrm{~d}, 1 \mathrm{H}, J=$ $8.1 \mathrm{~Hz})$; 7.78-7.85 (m, 2H); 7.91 (d, $1 \mathrm{H}, J=8.2 \mathrm{~Hz})$.

${ }^{13} \mathrm{C} \mathrm{NMR}\left(500 \mathrm{MHz}, \mathrm{CDCl}_{3}\right): \delta_{\mathrm{C}} 13.3,14.3,21.4,21.9$, $30.5,42.1,51.8,76.8,77.6,109.8,110.2,111.1,119.5$, 121.5, 122.6, 127.6, 138.0, 166.1. MS(EI): $\mathrm{m} / z=283$ $\left[\mathrm{M}^{+}\right]$

2.217 Methyl 1-benzyl-2-(hex-1-yn-1-yl)-1H-indole3-carboxylate (12g): $72 \%$ yield; Pale yellow solid; M.p. $134-136^{\circ} \mathrm{C}$; IR (KBr): 3346, 1699, 1461, 1213, $749 \mathrm{~cm}^{-1} .{ }^{1} \mathrm{H}$ NMR $\left(500 \mathrm{MHz}, \mathrm{CDCl}_{3}\right): \delta_{\mathrm{H}} 0.90(\mathrm{t}$, $3 \mathrm{H}, J=7.6 \mathrm{~Hz}) ; 1.35-1.44(\mathrm{~m}, 4 \mathrm{H}) ; 2.55(\mathrm{t}, 2 \mathrm{H}, J=$ $6.9 \mathrm{~Hz}) ; 4.05$ (s, 3H); 7.22-7.35 (m, 5H); 7.53-7.78 (m, $3 \mathrm{H}) ; 7.91(\mathrm{~d}, 1 \mathrm{H}, J=7.6 \mathrm{~Hz}) .{ }^{13} \mathrm{C}$ NMR $(500 \mathrm{MHz}$, $\left.\mathrm{CDCl}_{3}\right): \delta_{\mathrm{C}} 13.1,21.3,21.9,31.0,52.3,56.2,76.5$, 
77.4, 109.6, 110.2, 111.3, 119.4, 120.1, 122.4, 125.5, $126.6,127.8,128.0,135.4,136.8,165.4 . \mathrm{MS}(\mathrm{EI})$ : $m / z=345\left[\mathbf{M}^{+}\right]$

2.218 Methyl 1-benzyl-2-(hept-1-yn-1-yl)-1H-indole3-carboxylate $(\mathbf{1 2 h})$ : $67 \%$ yield; Yellow solid; M.p. 151-153 ${ }^{\circ} \mathrm{C}$; IR (KBr): 3317, 1703, 1455, 1218, 749 $\mathrm{cm}^{-1} .{ }^{1} \mathrm{H}$ NMR $\left(500 \mathrm{MHz}, \mathrm{CDCl}_{3}\right): \delta_{\mathrm{H}} 0.89(\mathrm{t}, 3 \mathrm{H}, J=$ $7.6 \mathrm{~Hz}) ; 1.27-1.51(\mathrm{~m}, 6 \mathrm{H}) ; 2.49$ (t, $2 \mathrm{H}, J=6.9 \mathrm{~Hz})$; $3.88(\mathrm{~s}, 3 \mathrm{H}) ; 5.55$ (s, 2H); 7.26-7.7.58 (m, 6H); 7.69$7.74(\mathrm{~m}, 2 \mathrm{H}) ; 7.95(\mathrm{~d}, 1 \mathrm{H}, J=8.1 \mathrm{~Hz}) .{ }^{13} \mathrm{C} \mathrm{NMR}$ $\left(500 \mathrm{MHz}, \mathrm{CDCl}_{3}\right): \delta_{\mathrm{C}} 14.3,21.5,28.3,30.5,30.8$, 51.9, 55.5, 78.7, 79.9, 109.5, 111.1, 111.7, 120.1, 121.2, $122.4,125.4,126.3,126.9,127.5,135.3,137.3,167.5$. $\mathrm{MS}(\mathrm{EI}): m / z=359\left[\mathrm{M}^{+}\right]$

2.219 Methyl 1-benzyl-2-(3-hydroxy-3-methylbut-1yn-1-yl)-1H-indole-3-carboxylate (12i): $65 \%$ yield; Colourless paste; IR $\left(\mathrm{CH}_{2} \mathrm{Cl}_{2}\right): 3489,3401,1702$, 1449, 1219, $768 \mathrm{~cm}^{-1}{ }^{1} \mathrm{H}$ NMR (500 $\left.\mathrm{MHz}, \mathrm{CDCl}_{3}\right)$ : $\delta_{\mathrm{H}} 1.55(\mathrm{~s}, 6 \mathrm{H}) ; 2.64(\mathrm{brs}, 1 \mathrm{H}) ; 3.77(\mathrm{~s}, 3 \mathrm{H}) ; 5.46(\mathrm{~s}$, 2H); 7.19-7.37 (m, 6H); 7.49-7.65 (m, 2H); 7.77-7.84 $(\mathrm{m}, 1 \mathrm{H}) \cdot{ }^{13} \mathrm{C}$ NMR $\left(500 \mathrm{MHz}, \mathrm{CDCl}_{3}\right): \delta_{\mathrm{C}} 33.1,50.9$, $55.8,77.7,80.8,110.9,111.9,112.8,120.3,121.5$, 122.3, 125.4, 126.5, 128.4, 128.7, 136.8, 138.4, 166.0. $\operatorname{MS}(\mathrm{EI}): m / z=348\left[\mathrm{M}^{+}+1\right]$

2.2110 Methyl 1-benzyl-2-(5-hydroxypent-1-yn-1-yl)1H-indole-3-carboxylate (12j): $60 \%$ yield; Colourless paste; IR $\left(\mathrm{CH}_{2} \mathrm{Cl}_{2}\right): 3456,3389,1688,1458,1212$, $745 \mathrm{~cm}^{-1}{ }^{1} \mathrm{H}$ NMR $\left(500 \mathrm{MHz}, \mathrm{CDCl}_{3}\right): \delta_{\mathrm{H}} 1.63-1.68$ $(\mathrm{m}, 2 \mathrm{H}) ; 2.52$ (brs, $1 \mathrm{H}) ; 2.55(\mathrm{t}, 2 \mathrm{H}, J=6.9 \mathrm{~Hz})$; $3.55-3.63(\mathrm{~m}, 2 \mathrm{H}) ; 3.93(\mathrm{~s}, 3 \mathrm{H}) ; 5.45(\mathrm{~s}, 2 \mathrm{H}) ; 7.28-$ $7.53(\mathrm{~m}, 6 \mathrm{H}) ; 7.62-7.68(\mathrm{~m}, 2 \mathrm{H}) ; 7.72-7.76(\mathrm{~m}, 1 \mathrm{H})$. ${ }^{13} \mathrm{C}$ NMR (500 MHz, $\left.\mathrm{CDCl}_{3}\right): \delta_{\mathrm{C}} 14.8,31.5,52.4,54.9$, $62.1,79.9,86.7,109.2,109.8,110.8,119.1,120.3$, $121.7,125.7,126.5,127.2,128.5,138.5,139.1,161.1$. $\operatorname{MS}(\mathrm{EI}): m / z=348\left[\mathrm{M}^{+}+1\right]$

$2.2 \mathrm{~m}$ General procedure for the alkaline hydrolysis of 2-ethynyl-indole-3-carboxylic acid methyl ester 13a-j: To a solution of methanol (3 mL), ethanol (1 mL) and water $(2 \mathrm{~mL})$ was added 2-ethynyl-indole-3-carboxylate $(500 \mathrm{mg})$ and stirred at room temperature for 5 min. To this reaction mixture was added $\mathrm{NaOH}(1.5$ equiv) and stirred at $75^{\circ} \mathrm{C}$ for $1 \mathrm{~h}$. After completion of the reaction as indicated by TLC, the reaction mixture was concentrated under reduced pressure. The residue was quenched with water $(10 \mathrm{~mL})$ and extracted with $\mathrm{Et}_{2} \mathrm{O}(3 \times 15 \mathrm{~mL})$ to remove the organic impurities. The aqueous extract was acidified ( $\mathrm{pH}=1$ to 2 ) with $10 \%$ $\mathrm{HCl}$ and extracted with EtOAc $(3 \times 15 \mathrm{~mL})$. The combined organic extract was dried over anhydrous $\mathrm{Na}_{2} \mathrm{SO}_{4}$ and concentrated under reduced pressure to afford pure product (13a-j), which is used for the next step without purification.

$2.2 \mathrm{n}$ General procedure for the synthesis of pyrano [4,3-b]-indol-1(5H)-ones $\mathbf{1 4 a - j :}$ To a mixture of 2ethynyl-indole-3-carboxylic acid $\mathbf{1 3 a} \mathbf{a}-\mathbf{j}(1.0 \mathrm{mmoL})$ in acetonitrile $(1 \mathrm{~mL})$ under $\mathrm{N}_{2}$ atmosphere was added $\mathrm{AuCl}_{3}(5 \mathrm{~mol} \%)$ and refluxed for the specified time (table 2). After completion of the reaction as indicated by TLC, the reaction mixture was concentrated under reduced pressure and poured into water, and extracted with ethyl acetate $(3 \times 10 \mathrm{~mL})$. The organic layer was dried over anhydrous $\mathrm{Na}_{2} \mathrm{SO}_{4}$, filtered, concentrated, and purified by column chromatography on silica gel using petroleum ether/ethyl acetate to afford the pure product.

2.2n1 5-Methyl-3-phenylpyrano[4,3-b]indol-1(5H)one (14a): 80\% yield; Colourless solid; M.p. 77$79^{\circ} \mathrm{C}$; IR (KBr): 3398, 1708, 1476, 11198, 1166, 758 $\mathrm{cm}^{-1} .{ }^{1} \mathrm{H} \mathrm{NMR}\left(500 \mathrm{MHz}, \mathrm{CDCl}_{3}\right): \delta_{\mathrm{H}} 4.00(\mathrm{~s}, 3 \mathrm{H})$; $6.38(\mathrm{~s}, 1 \mathrm{H}) ; 7.30-7.45(\mathrm{~m}, 5 \mathrm{H}) ; 7.62-7.76(\mathrm{~m}, 3 \mathrm{H})$; $8.01(\mathrm{~d}, 1 \mathrm{H}, J=6.9 \mathrm{~Hz}) .{ }^{13} \mathrm{C} \mathrm{NMR}\left(500 \mathrm{MHz}, \mathrm{CDCl}_{3}\right)$ : $\delta_{\mathrm{C}} 33.9,98.3,108.5,109.9,120.0,121.9,122.1$, 125.0, 125.8, 127.4, 127.7, 128.1, 130.4, 136.7, 160.1, 165.4. MS(EI): $m / z=275[\mathrm{M}-\mathrm{H}]^{-}$; Anal. Calcd for $\mathrm{C}_{18} \mathrm{H}_{13} \mathrm{NO}_{2}$ : C, 78.53; H, 4.76; N, 5.09\%. Found: C, 79.01.49; H, 4.69; N, 4.98\%.

\section{2n2 5-Ethyl-3-phenylpyrano[4,3-b]indol-1(5H)-}

one (14b): $78 \%$ yield; Colourless solid; M.p. 83$85^{\circ} \mathrm{C}$; IR (KBr): 3388, 1715, 1475, 1230, 1055, 775 $\mathrm{cm}^{-1} .{ }^{1} \mathrm{H}$ NMR $\left(500 \mathrm{MHz}, \mathrm{CDCl}_{3}\right): \delta_{\mathrm{H}} 1.28(\mathrm{t}, 3 \mathrm{H}, J$ $=7.6 \mathrm{~Hz}) ; 4.58(\mathrm{q}, 2 \mathrm{H}, J=7.6 \mathrm{~Hz}) ; 6.40(\mathrm{~s}, 1 \mathrm{H})$;

Table 2. $\mathrm{AuCl}_{3}$ catalyzed synthesis of pyrano[4,3-b] indol-1 $(5 H)$-ones.

\begin{tabular}{lcccc}
\hline Entry & Substrate & Product $^{\mathrm{a}}$ & Time (min) & Yield (\%) $^{\mathrm{b}}$ \\
\hline 1 & $\mathbf{1 3 a}$ & $\mathbf{1 4 a}$ & 50 & 80 \\
2 & $\mathbf{1 3 b}$ & $\mathbf{1 4 b}$ & 60 & 78 \\
3 & $\mathbf{1 3 c}$ & $\mathbf{1 4 c}$ & 90 & 75 \\
4 & $\mathbf{1 3 d}$ & $\mathbf{1 4 d}$ & 40 & 81 \\
5 & $\mathbf{1 3 e}$ & $\mathbf{1 4 e}$ & 90 & 74 \\
6 & $\mathbf{1 3 f}$ & $\mathbf{1 4 f}$ & 90 & 73 \\
7 & $\mathbf{1 3 g}$ & $\mathbf{1 4 g}$ & 90 & 67 \\
8 & $\mathbf{1 3 h}$ & $\mathbf{1 4 h}$ & 90 & 65 \\
9 & $\mathbf{1 3 i}$ & $\mathbf{1 4 i}$ & 90 & 47 \\
10 & $\mathbf{1 3 j}$ & $\mathbf{1 4 j}$ & 90 & 42 \\
\hline
\end{tabular}

${ }^{\mathrm{a}}$ All the Products were characterized by IR, ${ }^{1} \mathrm{H}$ NMR, ${ }^{13} \mathrm{C}$ NMR and MS

${ }^{\mathrm{b}}$ Isolated yield after column chromatography 
7.33-7.49 (m, 5H); 7.60-7.77 (m, 3H); $7.98(\mathrm{~d}, 1 \mathrm{H}$, $J=8.4 \mathrm{~Hz}) \cdot{ }^{13} \mathrm{C}$ NMR $\left(500 \mathrm{MHz}, \mathrm{CDCl}_{3}\right): \delta_{\mathrm{C}} 15.5$, 45.3, 98.1, 108.3, 109.7, 120.2, 121.1, 122.0, 124.6, 125.5, 127.1, 127.6, 128.4, 130.0, 136.4, 160.3, 165.2. MS(EI): $m / z=289\left[\mathrm{M}+\mathrm{NH}_{4}\right]^{+}$; Anal. Calcd for $\mathrm{C}_{19} \mathrm{H}_{15} \mathrm{NO}_{2}$ : C, 78.87; H, 5.23; N, 4.84\%. Found: C, $79.21 ; \mathrm{H}, 5.16 ; \mathrm{N}, 4.75 \%$.

2.2n3 5-Butyl-3-phenylpyrano[4,3-b]indol-1(5H)-one $(14 c)$ : $75 \%$ yield; Colourless solid; M.p. $100-102^{\circ} \mathrm{C}$; IR (KBr): 3401, 2952, 1721, 1065, $753 \mathrm{~cm}^{-1} \cdot{ }^{1} \mathrm{H}$ NMR $\left(500 \mathrm{MHz}, \mathrm{CDCl}_{3}\right): \delta_{\mathrm{H}} 0.91(\mathrm{t}, 3 \mathrm{H}, J=7.6 \mathrm{~Hz}) ; 1.42-$ $1.78(\mathrm{~m}, 4 \mathrm{H}) ; 4.18(\mathrm{t}, 2 \mathrm{H}, J=6.9 \mathrm{~Hz}) ; 6.31(\mathrm{~s}, 1 \mathrm{H})$; $7.32-7.49(\mathrm{~m}, 5 \mathrm{H}) ; 7.61-781(\mathrm{~m}, 3 \mathrm{H}) ; 8.02(\mathrm{~d}, 1 \mathrm{H}, J$ $=7.6 \mathrm{~Hz}) .{ }^{13} \mathrm{C} \mathrm{NMR}\left(500 \mathrm{MHz}, \mathrm{CDCl}_{3}\right): \delta_{\mathrm{C}} 13.2,20.6$, $33.9,54.7,97.9,108.9,109.9,120.8,121.8,122.5$, 124.3, 125.8, 127.7, 127.9, 128.8, 130.7, 136.7, 1609, 165.9. $\mathrm{MS}(\mathrm{EI}): m / z=316[\mathrm{M}-\mathrm{H}]^{-}$; Anal. Calcd for $\mathrm{C}_{21} \mathrm{H}_{19} \mathrm{NO}_{2}$ : C, 79.47; H, 6.03; N, 4.41\%. Found: C, $78.99 ; \mathrm{H}, 6.11 ; \mathrm{N}, 4.55 \%$.

2.2n4 5-Benzyl-3-phenylpyrano[4,3-b]indol-1(5H)one $(\mathbf{1 4 d})$ : $81 \%$ yield; Pale yellow solid; M.p. 210$212^{\circ} \mathrm{C} ; v_{\max }(\mathrm{KBr}) / \mathrm{cm}^{-1} 3364,2960,2921,2850,2358$, 2345, 2079, 1715, 1455, 1260, 799; ${ }^{1} \mathrm{H}$ NMR (500 $\left.\mathrm{MHz}, \mathrm{CDCl}_{3}\right): \delta_{\mathrm{H}} 5.51(\mathrm{~s}, 2 \mathrm{H}) ; 6.94(\mathrm{~s}, 1 \mathrm{H}) ; 7.11-7.17$ $(\mathrm{m}, 2 \mathrm{H})$; 7.30-7.40 (m, 6H); 7.42-7.50 (m, 3H); 7.85$7.95(\mathrm{~m}, 2 \mathrm{H}) ; 8.25-8.35(\mathrm{~m}, 1 \mathrm{H}) ;{ }^{13} \mathrm{C}$ NMR $(500 \mathrm{MHz}$, $\left.\mathrm{CDCl}_{3}\right): \delta_{\mathrm{C}} 47.7,91.4,100.9,110.3,121.9,123.3$, 124.8, 125.3, 126.1, 126.6, 128.6, 129.3, 129.6, 130.8, $132.6,135.9,139.2,146.7,159.1,159.6 ; \mathrm{MS}(\mathrm{EI})$ : $m / z=352[\mathrm{M}+\mathrm{H}]^{+}$; Anal. Calcd for $\mathrm{C}_{24} \mathrm{H}_{17} \mathrm{NO}_{2}: \mathrm{C}$, 82.03; H, 4.88; N, 3.99\%. Found: C, 81.79; H, 4.95; N, $4.09 \%$.

2.2n5 3-Butyl-5-methylpyrano[4,3-b]indol-1(5H)-one (14e): $\quad 74 \%$ yield; Colourless solid; M.p. $87-89^{\circ} \mathrm{C}$; IR (KBr): 3055, 3012, 17 01, 1622, 1611, $812 \mathrm{~cm}^{-1} .{ }^{1} \mathrm{H}$ NMR $\left(500 \mathrm{MHz}, \mathrm{CDCl}_{3}\right): \delta_{\mathrm{H}} 0.91(\mathrm{t}, 3 \mathrm{H}, J=7.6 \mathrm{~Hz})$; $1.27-1.44(\mathrm{~m}, 4 \mathrm{H}) ; 4.04(\mathrm{~s}, 3 \mathrm{H}) ; 5.87(\mathrm{~s}, 1 \mathrm{H}) ; 7.62$ $(\mathrm{d}, 1 \mathrm{H}, J=8.1 \mathrm{~Hz}) ; 7.69-7.75(\mathrm{~m}, 2 \mathrm{H}) ; 7.96(\mathrm{~d}, 1 \mathrm{H}$, $J=8.1 \mathrm{~Hz}) .{ }^{13} \mathrm{C}$ NMR $\left(500 \mathrm{MHz}, \mathrm{CDCl}_{3}\right): \delta_{\mathrm{C}} 14.1$, $22.5,25.9,33.2,33.9,99.9,109.8,110.2,119.2,122.3$, 123.2, 127.8, 138.9, 161.4, 167.8. MS(EI): $m / z=255$ $\left[\mathrm{M}^{+}\right]$. Anal. Calcd for $\mathrm{C}_{16} \mathrm{H}_{17} \mathrm{NO}_{2}: \mathrm{C}, 75.27 ; \mathrm{H}, 6.71$; N, 5.49\%. Found: C, 74.89; H, 6.79; N, 5.61\%.

2.2n6 3-Butyl-5-ethylpyrano[4,3-b]indol-1(5H)-one (14f): $73 \%$ yield; Colourless solid; M.p. $94-96^{\circ} \mathrm{C}$; IR (KBr): 3148, 2978, 1712, 1625, 1605, $834 \mathrm{~cm}^{-1} .{ }^{1} \mathrm{H}$ NMR $\left(500 \mathrm{MHz}, \mathrm{CDCl}_{3}\right): \delta_{\mathrm{H}} 0.88(\mathrm{t}, 3 \mathrm{H}, J=6.9 \mathrm{~Hz})$; $1.28(\mathrm{t}, 3 \mathrm{H}, J=7.6 \mathrm{~Hz}) ; 1.31-1.1 .38(\mathrm{~m}, 4 \mathrm{H}) ; 1.89$ (t,
$2 \mathrm{H}, J=7.1 \mathrm{~Hz}) ; 4.49(\mathrm{q}, 2 \mathrm{H}, J=7.6 \mathrm{~Hz}) ; 5.86(\mathrm{~s}, 1 \mathrm{H})$; 7.44-7.56 (m, 3H); 7.67-7.74 (m, 1H). ${ }^{13} \mathrm{C}$ NMR (500 $\left.\mathrm{MHz}, \mathrm{CDCl}_{3}\right): \delta_{\mathrm{C}} 13.9,15.2,22.5,26.4,33.6,43.6$, 98.7, 109.2, 110.8, 119.8, 122.9, 123.6, 127.2, 139.4, 161.5, 166.4. MS(EI): $m / z=269\left[\mathrm{M}^{+}\right]$. Anal. Calcd for $\mathrm{C}_{17} \mathrm{H}_{19} \mathrm{NO}_{2}$ : C, 75.81; H, 7.11; N, 5.20\%. Found: C, 76.25; H, 7.19; N, 5.32\%.

2.2n7 5-Benzyl-3-butylpyrano[4,3-b]indol-1(5H)-one (14g): $67 \%$ yield; Colourless solid; M.p. $103-105^{\circ} \mathrm{C}$; IR (KBr): 3148, 3025, 1705, 1625, 832, $717 \mathrm{~cm}^{-1} \cdot{ }^{1} \mathrm{H}$ NMR $\left(500 \mathrm{MHz}, \mathrm{CDCl}_{3}\right): \delta_{\mathrm{H}}(0.91(\mathrm{t}, 3 \mathrm{H}, J=7.6 \mathrm{~Hz})$; $1.29-1.38(\mathrm{~m}, 4 \mathrm{H}) ; 2.00(\mathrm{t}, 2 \mathrm{H}, J=6.9 \mathrm{~Hz}) ; 5.82(\mathrm{~s}$, $2 \mathrm{H}) ; 5.91(\mathrm{~s}, 3 \mathrm{H}) ; 7.22-7.48(\mathrm{~m}, 7 \mathrm{H}) ; 7.77(\mathrm{~d}, 1 \mathrm{H}, J$ $=8.1 \mathrm{~Hz}) ; 7.94(\mathrm{~d}, 1 \mathrm{H}, J=8.1 \mathrm{~Hz}) .{ }^{13} \mathrm{C}$ NMR $(500$ $\mathrm{MHz}, \mathrm{CDCl}_{3}$ ): $\delta_{\mathrm{C}} 14.2,22.5,25.9,33.3,51.3,100.1$, $108.5,110.1,119.9,122.4,125.3,125.7,127.7,129.2$, $133.9,139.9,161.8,167.6 . \mathrm{MS}(\mathrm{EI}): m / z=330[\mathrm{M}-$ $\mathrm{H}]^{-}$; Anal. Calcd for $\mathrm{C}_{22} \mathrm{H}_{21} \mathrm{NO}_{2}: \mathrm{C}, 79.73 ; \mathrm{H}, 6.39 ; \mathrm{N}$, 4.23\%. Found: C, 80.09; H, 6.50; N, 4.37\%.

2.2n8 5-Benzyl-3-pentylpyrano[4,3-b]indol-1(5H)-one (14h): $65 \%$ yield; Colourless solid; M.p. $120-122^{\circ}$ C; IR (KBr): 3155, 3035-2865, 1715, 1625, 1610, 848 $\mathrm{cm}^{-1} .{ }^{1} \mathrm{H}$ NMR $\left(500 \mathrm{MHz}, \mathrm{CDCl}_{3}\right): \delta_{\mathrm{H}} 0.89(\mathrm{t}, 3 \mathrm{H}$, $J=6.6 \mathrm{~Hz}) ; 1.25-1.33(\mathrm{~m}, 4 \mathrm{H}) ; 1.66-1.80(\mathrm{~m}, 2 \mathrm{H})$; $2.55(\mathrm{t}, 2 \mathrm{H}, J=8.1 \mathrm{~Hz}) ; 5.39(\mathrm{~s}, 2 \mathrm{H}) ; 6.25(\mathrm{~s}, 1 \mathrm{H})$; 7.02-7.11 (m, 3H); 7.24-7.33 (m, 6H); 7.00-8.04 (m, 1H). ${ }^{13} \mathrm{C}$ NMR $\left(500 \mathrm{MHz}, \mathrm{CDCl}_{3}\right): \delta_{\mathrm{C}} 14.2,22.6$, 27.0, 31.2, 34.5, 47.6, 92.8, 99.5, 110.0, 121.3, 122.9, $124.5,126.2,128.1,129.2,135.6,138.3,146.6,160.1$, 164.5. $\mathrm{MS}(\mathrm{EI}): \mathrm{m} / z=346[\mathrm{M}+\mathrm{H}]^{+}$; Anal. Calcd for $\mathrm{C}_{23} \mathrm{H}_{23} \mathrm{NO}_{2}$ : C, 79.97; H, 6.71; N, 4.05\%. Found: C, $80.25 ; \mathrm{H}, 6.77 ; \mathrm{N}, 4.16 \%$.

2.2n9 5-Benzyl-3-(2-hydroxypropan-2-yl)pyrano[4,3b]indol-1(5H)-one (14i): $47 \%$ yield; Colourless solid; M.p. $155-157^{\circ} \mathrm{C}$; IR (KBr): 3589, 3449, 31152915, 1700, 1681, $834 \mathrm{~cm}^{-1}$. ${ }^{1} \mathrm{H}$ NMR $(500 \mathrm{MHz}$, $\left.\mathrm{CDCl}_{3}\right): \delta_{\mathrm{H}} 1.65(\mathrm{~s}, 6 \mathrm{H}) ; 3.02$ (brs, $\left.1 \mathrm{H}\right) ; 5.30(\mathrm{~s}, 2 \mathrm{H})$; $6.81(\mathrm{~s}, 1 \mathrm{H}) ; 6.99-7.06(\mathrm{~m}, 2 \mathrm{H}) ; 7.22-7.37(\mathrm{~m}, 6 \mathrm{H})$; 8.19-8.25 (m, 1H). ${ }^{13} \mathrm{C}$ NMR $\left(500 \mathrm{MHz}, \mathrm{CDCl}_{3}\right): \delta_{\mathrm{C}}$ 28.6, 47.0, 71.9, 89.8, 99.5, 110.0, 121.2, 122.9, 124.1, 124.6, 126.2, 128.0, 129.0, 135.6, 138.3, 146.4, 159.5, 168.5. MS(EI): $m / z=332[\mathrm{M}-\mathrm{H}]^{+}$; Anal. Calcd for $\mathrm{C}_{21} \mathrm{H}_{19} \mathrm{NO}_{3}$ : C, 75.66; H, 5.74; N, 4.20\%. Found: C, $76.01 ; \mathrm{H}, 5.65 ; \mathrm{N}, 4.08 \%$.

2.2n10 5-Benzyl-3-(3-hydroxypropan-2-yl)pyrano[4, 3-b]indol-1(5H)-one (14j): $42 \%$ yield; Orange solid; M.p. $148-150^{\circ} \mathrm{C}$; IR (KBr): 3415, 2925, 2859, 1695 , 1559, 832, $789 \mathrm{~cm}^{-1} .{ }^{1} \mathrm{H}$ NMR (500 $\mathrm{MHz}, \mathrm{CDCl}_{3}$ ): 
$\delta_{\mathrm{H}} 1.69$ (brs, 1H); 1.91-2.05 (m, 2H), $2.75(\mathrm{t}, 2 \mathrm{H}, J=$ $7.6 \mathrm{~Hz}), 3.70(\mathrm{t}, 2 \mathrm{H}, J=6.4 \mathrm{~Hz}), 5.38(\mathrm{~s}, 2 \mathrm{H}), 6.35$ (s, 1H), 7.03-7.12 (m, 2H); 7.22-7.38 (m, 6H); 8.15$8.25(\mathrm{~m}, 1 \mathrm{H}) .{ }^{13} \mathrm{C}$ NMR $\left(500 \mathrm{MHz}, \mathrm{CDCl}_{3}\right): \delta_{\mathrm{C}} 30.3$, 31.1, 47.2, 61.9, 93.0, 99.6, 110.0, 121.5, 122.9, 124.6, 124.5, 126.3, 128.1, 129.3, 135.7, 138.5, 146.7, 160.1, 163.5. MS(EI): $m / z=351\left[\mathrm{M}+\mathrm{NH}_{4}\right]^{+}$; Anal. Calcd for $\mathrm{C}_{21} \mathrm{H}_{19} \mathrm{NO}_{3}$ : C, 75.66; H, 5.74; N, 4.20\%. Found: C, 75.35; H, 5.79; N, 4.28\%.

\subsection{Experimental procedure for the evaluation of cytotoxicty}

The HeLa cells were seeded into 96-well plates in $100 \mu \mathrm{L}$ of medium containing $5 \%$ fetal bovine serum (FBS), at plating density of 10,000 cells/well and incubated at $37^{\circ} \mathrm{C}, 5 \% \mathrm{CO}_{2}, 95 \%$ air and $100 \%$ relative humidity for $24 \mathrm{~h}$ prior to addition of samples. The samples were solubilized in DMSO and diluted in serum free medium. After $24 \mathrm{~h}, 100 \mu \mathrm{L}$ of the medium containing the samples at various concentrations were added and incubated at $37^{\circ} \mathrm{C}, 5 \% \mathrm{CO}_{2}$, $95 \%$ air and $100 \%$ relative humidity for $48 \mathrm{~h}$. Triplicate was maintained and the medium containing without samples were served as control. After $48 \mathrm{~h}, 15 \mu \mathrm{L}$ of MTT $(5 \mathrm{mg} / \mathrm{mL})$ in Dulbecco's phosphate buffered saline (DPBS) was added to each well and incubated at $37^{\circ} \mathrm{C}$ for $4 \mathrm{~h}$. The medium with MTT was then flicked off and the formed formazan crystals were solubilized in $100 \mu \mathrm{L}$ of DMSO and then the absorbance was measured at $570 \mathrm{~nm}$ using micro plate reader. The percentage growth of inhibition of was calculated by comparing the results of the test with those of the control using the formula: $\%$ inhibition $=\left(\mathrm{A}_{\mathrm{C}}-\mathrm{A}_{\mathrm{T}}\right) / \mathrm{A}_{\mathrm{C}} \times 100$, where $A_{C}$ is the absorbance of control and $A_{T}$ is the absorbance of test. From the results nonlinear regression graph was plotted between \% cell growth inhibition and $\log _{10}$ concentration $(\mu \mathrm{M})$. The half maximal inhibitory concentration ( $\mathrm{IC}_{50}$ value) was determined using GraphPad Prism software.

\subsection{Molecular docking}

Molecular docking simulation was performed using the AutoDock Tools (ADT) version 1.5.6 and AutoDock version 4.2.5.1 docking program. Three dimensional structure of VHR receptor was obtained from the Protein Data Bank (PDB ID: 3F81). The co-crystallized ligand in the 3F81 structure was removed. Then, the water molecules present with the crystal were deleted, the polar hydrogen atoms were added, lower occupancy residue structures were deleted, and any incomplete side chains were replaced using the ADT. Gasteiger charges were added to each atom and merged the nonpolar hydrogen atoms to the protein structure. The hydrogen bond distance between donor and acceptor atoms was defined as $1.9 \AA$ with a tolerance of $0.5 \AA$, and the acceptor- hydrogen-donor angle was not less than $120^{\circ}$. Then, the structures were saved in PDBQT file format for further studies in ADT. ChemDraw Ultra 7.0 (ChemOffice 2002) was used to draw the Ligand 2D structures. Then, Chem3D Ultra 7.0 was used to convert 2D structure into 3D, and semi-empirical AM1 method was used to minimize the energy. Minimum RMS gradient of 0.100 was set in each iteration to minimize the energy. All structures were saved as .pdb file format for input to ADT. All the ligand structures were then saved in PDBQT file format, to carry out docking in ADT. A grid box with dimension of $40 \times 40 \times 40 \AA^{3}$ with $0.375 \AA$ spacing centred on $-0.908,0.681,-6.463$ was created around the binding site of co-crystallised ligand on 3F81 protein using ADT. The centre of the box was set at co-crystallised ligand centre and grid energy calculations were carried out. AutoDock docking calculation was done using default parameters and 50 docked conformations were generated for each compound. Genetic algorithms were used to calculate the energy of the binding interactions. The outputs were exported to PyMOL for visual inspection of the binding modes and interactions of the compounds with amino acid residues in the active sites.

\section{Results and Discussion}

\subsection{Chemistry}

3.1a Chemical synthesis of pyrano[3,4-b]indol-1(9H)ones: The synthetic pathway of pyrano[3,4- $b]$ indol$1(9 H)$-ones is outlined in scheme 1 . Indole-2-carboxylic acid 1a-b was esterified with methanol using catalytic sulphuric acid to afford the corresponding methyl ester 2a-b. ${ }^{7}$ The esters were then subjected to C3iodination using molecular iodine to afford 3-iodoindole-2-carboxylate $\mathbf{3 a - b}{ }^{8} \mathrm{~N}$-alkyl-3-iodo-indole-2carboxylate $4 \mathbf{a}-\mathrm{g}$ was obtained by $\mathrm{N}$-alkylation reaction of 3a-b using respective alkyl halide and base. ${ }^{9}$ 3(Ethynyl)-indole-2-carboxylate $\mathbf{5 a - j}$ was obtained by coupling terminal alkynes with 3-iodo indoles $\mathbf{3 a - b}$ and 4a-j under standard Sonagashira condition. ${ }^{10}$ Hydrolysis of 5a-j was achieved using aqueous sodium hydroxide in an ethanol-methanol solution to give 3-(ethynyl)indole-2-carboxylic acid $\mathbf{6 a - j} .{ }^{11}$ Having synthesized the starting materials in satisfactory yields, we then focused our attention on the cyclization of substrates $\mathbf{6 a - j}$. 


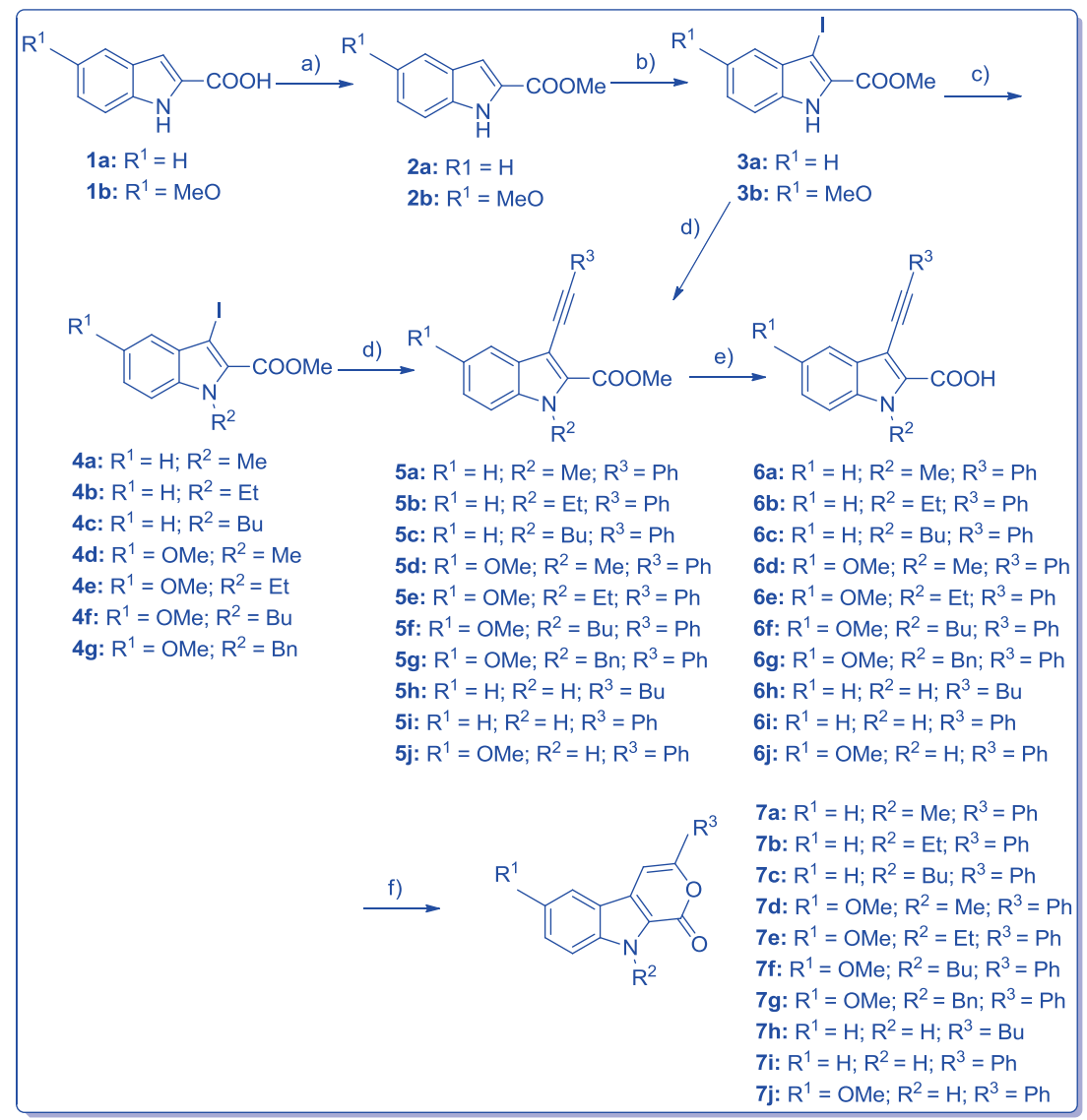

Scheme 1. (a) $\mathrm{H}_{2} \mathrm{SO}_{4}$ (catalytic), $\mathrm{MeOH}$, reflux, $24 \mathrm{~h}$ (b) $\mathrm{I}_{2}$ (1.2 equiv.), $\mathrm{KOH}$ (3.0 equiv.), DMF, rt, 6 h (c) (for 4a, 4b, 4d and 4e) $\mathrm{NaH}$ (2.0 equiv), DMF, $30 \mathrm{~min}$ at $0^{\circ} \mathrm{C}$ then $\mathrm{R}^{2} \mathrm{X}\left(3.0\right.$ equiv), $0^{\circ} \mathrm{C}$ to $\mathrm{rt}, 6 \mathrm{~h}$ (for $\mathbf{4 c}, \mathbf{4 f}$ and $\left.\mathbf{4 g}\right) \mathrm{KOH}(3.0$ equiv), $\mathrm{DMSO}, 30 \mathrm{~min}$ at $0^{\circ} \mathrm{C}$ then $\mathrm{R}^{2} \mathrm{X}\left(5.0\right.$ equiv), $0^{\circ} \mathrm{C}$ to $\mathrm{rt}, 6 \mathrm{~h}(\mathrm{~d}) \mathrm{PdCl}_{2}\left(\mathrm{Ph}_{3} \mathrm{P}\right)_{2}(5 \mathrm{~mol} \%), \mathrm{CuI}(5 \mathrm{~mol} \%)$, alkyne, $(1.1 \mathrm{equiv})$, $\mathrm{Et}_{3} \mathrm{~N}, 6$ h, rt (e) $\mathrm{NaOH}$ (1.5 equiv), $\mathrm{MeOH} / \mathrm{EtOH} / \mathrm{H}_{2} \mathrm{O}(3: 1: 2), 75^{\circ} \mathrm{C}, 1 \mathrm{~h}$ (f) $\mathrm{AuCl}_{3}(5 \mathrm{~mol} \%), \mathrm{MeCN}$, reflux.

Cycloisomerization of substrates $\mathbf{6 a - j}$ in the presence of $5 \mathrm{~mol} \%$ of $\mathrm{AuCl}_{3}$ in refluxing acetonitrile gave the pyranoindolones 7a-j with good to excellent yields as single regioisomer. The results were shown in table 1 , which indicate that the reaction proceeded at a short reaction time in $\mathrm{N}$-alkyl indoles than unsubstituted indoles. Significant increase in yield of the product was observed in $\mathrm{N}$-alkyl indoles $\mathbf{7 a - g}$, whereas a slight decrease in the product yield was observed in $\mathrm{N}$-unsubstituted indoles 7h-j. These observations suggest that the presence of electron releasing $\mathrm{N}$-alkyl group enhances the electron density of the triple bond, thus coordinating with the Lewis acidic $\mathrm{AuCl}_{3}$ with ease. The presence of electron releasing substituent (MeO-) in the aryl ring also enhances the reaction as evidenced by the short reaction time and excellent yield $\mathbf{7 d - g}$. The structures of all the synthesized compounds were confirmed by spectral data (FTIR, ${ }^{1} \mathrm{H}$ NMR, ${ }^{13} \mathrm{C}$ NMR and EI-MS) and elemental analyses. Pyrano[3,4- $b$ ]indol-1 $(9 H)$-one derivatives 7a-j showed $\mathrm{C}=\mathrm{O}$ stretching bands in the region of $1666-1714 \mathrm{~cm}^{-1}$ in their IR spectrum, indicating the presence of a $\delta$ - lactone ring. In ${ }^{1} \mathrm{H}$ NMR spectrum, a prominent singlet at $\delta_{\mathrm{H}}=6.62-7.76 \mathrm{ppm}$ ascertained the presence of C4-hydrogen of the indolone ring. In ${ }^{13} \mathrm{C}$ NMR spectrum the lactone carbonyl and $\mathrm{C} 4-$ carbon resonated at $\delta_{\mathrm{C}}=155.2-163.6$ and 97.1$98.5 \mathrm{ppm}$ respectively. All these findings confirmed the formation of products.

\section{1b Chemical synthesis of pyrano[4,3-b]indol-1(5H)-} ones: With an efficient protocol for the synthesis of pyrano[3,4- $b$ ]indol-1 $(9 H)$-ones in hand, we next set out to investigate the scope and limitations of our gold catalytic system towards the synthesis of its positional isomer, pyrano[4,3- $b]$ indol-1 $(5 H)$-ones. The required 2-(Ethynyl)-indole-2-carboxylic acids can be easily prepared according to standard literature procedures as shown in scheme 2. Vilsmeir bromoformylation of oxindole 8a affords 2-bromo-indole-3-carbaldehyde 9a in excellent yield. ${ }^{12}$ Oxidative esterification of 9a with oxone in methanol gave the ester 10a. ${ }^{13} \mathrm{~N}$ alkylation of 10a was performed with appropriate alkyl halide and base which results in the formation of $\mathrm{N}$-alkyl derivatives 11a-d. ${ }^{9}$ By subjecting 11a-d and terminal acetylenes under standard Sonogashira 


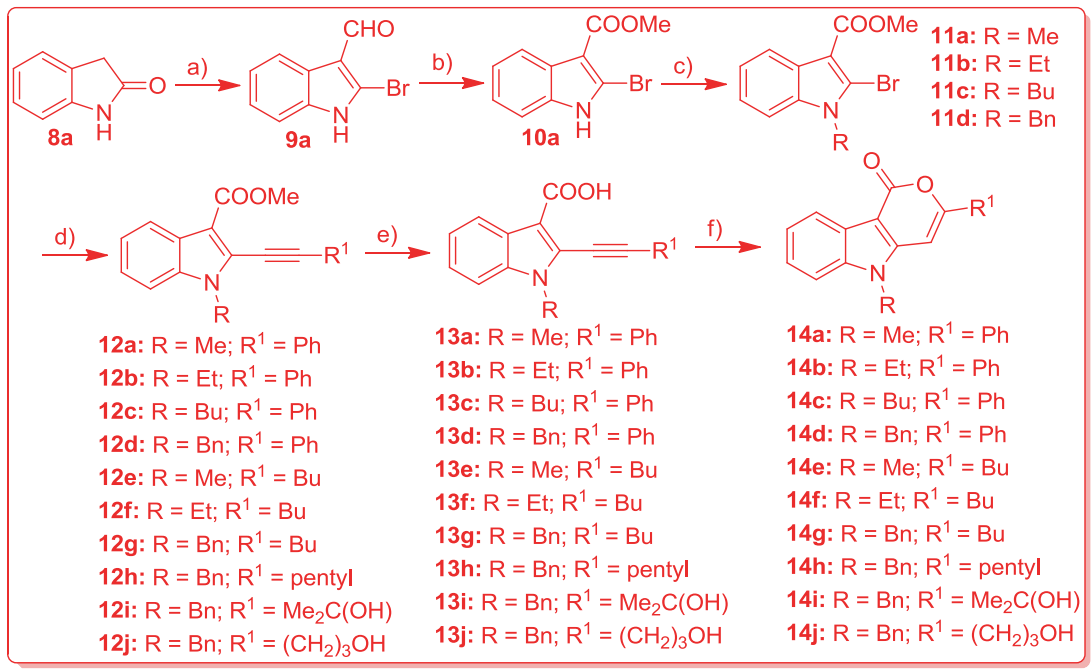

Scheme 2. (a) $\mathrm{POBr}_{3}$ (2.5 equiv.), $\mathrm{DMF}$ (10 equiv.), $\left(\mathrm{CH}_{2}\right)_{2} \mathrm{Cl}_{2}, 0^{\circ} \mathrm{C}$ to rt, $24 \mathrm{~h}$ (b) Oxone $\mathbb{R}(1.05$ equiv.), $\mathrm{MeOH}, \mathrm{rt} 3 \mathrm{~h}$ (c) (for 11a and 11b) $\mathrm{NaH}$ (2.0 equiv), DMF, 30 min at $0^{\circ} \mathrm{C}$ then $\mathrm{R}^{2} \mathrm{X}$ (3.0 equiv), $0^{\circ} \mathrm{C}$ to rt, $6 \mathrm{~h}$ (for, 11c and 11d) $\mathrm{KOH}(3.0$ equiv), DMSO, $30 \mathrm{~min}$ at $0^{\circ} \mathrm{C}$ then $\mathrm{R}^{2} \mathrm{X}\left(5.0\right.$ equiv), $0^{\circ} \mathrm{C}$ to $\mathrm{rt}, 6 \mathrm{~h}(\mathrm{~d}) \mathrm{Pd}_{(}\left(\mathrm{Ph}_{3} \mathrm{P}\right)_{4}(5 \mathrm{~mol} \%)$, $\mathrm{CuI}(5 \mathrm{~mol} \%)$, terminal alkyne, (1.1 equiv), $\mathrm{Et}_{3} \mathrm{~N}, 6 \mathrm{~h}, \mathrm{rt}$ (e) $\mathrm{NaOH}$ (1.5 equiv), $\mathrm{MeOH} / \mathrm{EtOH} / \mathrm{H}_{2} \mathrm{O}(3: 1: 2), 75^{\circ} \mathrm{C}, 1 \mathrm{~h}$ (f) $\mathrm{AuCl}_{3}(5 \mathrm{~mol} \%), \mathrm{MeCN}$, reflux.

cross-coupling reaction yields the acetylenic derivatives 12a-j. ${ }^{10}$ Alkaline hydrolysis of $\mathbf{1 2 a - j}$ affords the requisite 2-(ethynyl)-indole-3-carboxylic acid 13a-j. ${ }^{11}$ In the light of our previous study, ${ }^{3 \mathrm{~d}}$ we subjected the acetylenic precursors 13a-j with $5 \mathrm{~mol} \%$ of $\mathrm{AuCl}_{3}$ under refluxing condition. Gratifyingly, the reaction proceeds and affords the corresponding products 14a$\mathbf{j}$ in moderate to good chemical yields (table 2). It is noteworthy to mention that precursors 13aj led to reasonable conversion with only an increase of the reaction time as compared to its positional isomer $\mathbf{6 a - j}$. This can be attributed to the reduced electrophilicity of carboxylic acid in $\mathrm{C} 3$-indole (as in $\mathbf{1 3 a - j}$ ) compared to that of $\mathrm{C} 2$-indole (as in $\mathbf{6 a - j}$ ). The low yield observed in compounds $14 \mathbf{i}$ and $\mathbf{1 4} \mathbf{j}$ can be rationalized by the decrease in Lewis acidity of the catalyst by interacting with the hydroxyl function and eventually the catalytic efficiency of the overall process. Similar to our previous results, ${ }^{3 \mathrm{~d}}$ we found that the cycloisomerization follows 6-endodig regiochemistry leading to $\delta$-lactone and no $\gamma$-lactone was observed as evidenced by crude NMR analysis. This can be ascribed to the energetic inaccessibility or greater strain of 5-5 ring formation over 5-6 ring formation. The formation of $\delta$-lactone ring in all compounds was ascertained by stretching band between 1695 and $1721 \mathrm{~cm}^{-1}$ in their IR spectrum. In ${ }^{1} \mathrm{H}$ NMR spectrum a singlet between $\delta_{\mathrm{H}} 5.86$ and $6.81 \mathrm{ppm}$ were observed, characteristic of the C4hydrogen of 14a-j. Moreover all compounds exhibited two characteristic peaks in their ${ }^{13} \mathrm{C}$ NMR spectrum at $\delta_{\mathrm{C}}=97.9-100.1$ and $163.5-168.5 \mathrm{ppm}$, thus confirming the presence of C4-carbon and lactone carbonyl carbon of $\mathbf{1 4 a - j}$, respectively.

\subsection{Biology}

In pursuance of our on-going project on bio-active heterocycles, ${ }^{3 \mathrm{k}-\mathrm{t}}$ an attempt was made to evaluate the cytotoxicity of compounds (7a-j and 14a-j) against human adenocarcinoma cell lines. Towards this end, the MTT [3-(4,5-dimethylthiazo-2-yl)-2,5-diphenyltetrazolium bromide] cell proliferation assay was used to evaluate the cytotoxic activity of the synthesized compounds against HeLa cell lines. ${ }^{14}$ Results of the in vitro anticancer activity were compared with reference drug cisplatin. Analysis of the screening data (table 3) revealed that compounds $\mathbf{7 d}, \mathbf{7 e}$ and $\mathbf{7 j}$ showed comparable anticancer potency with $\mathrm{IC}_{50}$ values of 0.22 , 1.2 and $0.33 \mu \mathrm{M}$, respectively with respect to the reference drug, cisplatin $\left(\mathrm{IC}_{50}=0.08 \mu \mathrm{M}\right)$. The results indicated that the presence of methoxy substituent on the C-6 position was found to be essential for activity, since compounds without 6-MeO groups showed a significant loss of potency. A small substituent like methyl on the nitrogen atom $7 \mathbf{d}\left(\mathrm{IC}_{50}=0.22 \mu \mathrm{M}\right)$ exhibited maximum potency compared to other analogues. Replacement of the N-methyl group with an N-ethyl group 7e $\left(\mathrm{IC}_{50}=1.20 \mu \mathrm{M}\right)$ decreased the potency appreciably, whereas N-butyl group 7f $\left(\mathrm{IC}_{50}=5.00 \mu \mathrm{M}\right)$ showed even much reduced inhibitory potency. The loss of activity was observed due to the increase on group size from methyl to ethyl to butyl for compounds 7d-f. However, similar behaviour was not observed in molecules devoid of 6-MeO group such as $\mathbf{7 a}, \mathbf{7 b}$ and $\mathbf{7} \mathbf{c}$ as evidenced by the inconsistent $\mathrm{IC}_{50}$ values $(1.90,11.31$ and $3.20 \mu \mathrm{M}$, respectively). Although the reason was not clear, it was attributed to the favourable structural 
combination of 6-MeO and $\mathrm{N}$-alkyl groups to exhibit better anticancer activity. Interestingly, the absence of alkyl substituent on the indole nitrogen $\mathbf{7 j}\left(\mathrm{IC}_{50}=\right.$ $0.33 \mu \mathrm{M}$ ) seems to be the second most active among the tested compounds. In contrast, the related compound $7 \mathbf{i}\left(\mathrm{IC}_{50}=19.1 \mu \mathrm{M}\right)$ emerged as the least attractive compound in this series showing poor activity. A moderate cytotoxity was observed for compound with 3-butyl group $\mathbf{7 h}\left(\mathrm{IC}_{50}=2.60 \mu \mathrm{M}\right)$. Next, we turned our attention in comparing the SAR of the pyrano[4,3$b$ ]indol-1(5H)-one series 14a-j (table 3). From the analysis of the observed data, it was found that compound 14d possessing C3-phenyl and N-benzyl substituent showed highest activity $\left(\mathrm{IC}_{50}=0.69 \mu \mathrm{M}\right)$. Compound 14c which contains C3-butyl and N-butyl groups emerged as the second most active in the series $\left(\mathrm{IC}_{50}=1.11 \mu \mathrm{M}\right)$. However, replacement of N-butyl by a small group like methyl (14a) marginally reduced the inhibitory potency to $1.24 \mu \mathrm{M}$. By increasing the chain length to ethyl at the nitrogen atom (14b), a slight decrease in activity was observed $\left(\mathrm{IC}_{50}=1.41 \mu \mathrm{M}\right)$. Switching from phenyl to aliphatic chains such as butyl and pentyl as a C3-substituent (14e-h) exhibited only moderate potency with the $\mathrm{IC}_{50}$ values ranging between 1.63 and $1.92 \mu \mathrm{M}$. Compounds possessing tertiary and primary hydroxyl (14i and $\mathbf{1 4} \mathbf{j})$ emerged as less active among the tested series $\left(\mathrm{IC}_{5}=2.02\right.$ and $2.25 \mu \mathrm{M}$, respectively) suggesting the intolerance of polar substituent at the $\mathrm{C} 3$-site. These qualitative assessments revealed that the presence of C3-phenyl substituent (as in 14a-d) is essential for exhibiting good inhibitory potency. An overall comparison of the results suggested that pyrano[4,3- $b]$ indol-1 $(5 H)$-ones $\mathbf{1 4 a - j}$ exert consistent $\mathrm{IC}_{50}$ values $(0.69-2-89 \mu \mathrm{M}$ against the analogous positional isomers $\mathbf{7 a - j}(0.22-19.11 \mu \mathrm{M})$.

\subsection{Molecular docking}

In pharmaceutical drug design, the discovery of small molecules that predominantly undergo non-covalent interactions such as hydrogen bonding, van der Waals, $\pi-\pi$ and $\pi$-cationic interactions in protein-ligand binding is an important concept. ${ }^{15}$ This in silico approach involves the docking of synthesized compounds into the active site of the 3D structure of the target, followed by the calculation of free energy of binding (FEB) of the protein-ligand complex. The binding mode of the potent inhibitors was investigated using AutoDock Tools (ADT) version 1.5.6 and AutoDock version 4.2.5.1 docking program to rationalize the pharmacological results. ${ }^{16}$ To gain insights of the observed activity, we docked all the compounds to Vaccinia H1-Related (VHR) Phosphatase receptor (PDB ID:
Table 3. Anticancer potency of compounds $7 \mathbf{a}-\mathbf{j}$ and 14a-j in HeLa cell lines.

\begin{tabular}{lrc}
\hline Entry & Compound & $\mathrm{IC}_{50}(\mu \mathrm{M})$ \\
\hline 1 & $\mathbf{7 a}$ & 1.90 \\
2 & $\mathbf{7 b}$ & 11.31 \\
3 & $\mathbf{7 c}$ & 3.20 \\
4 & $\mathbf{7 d}$ & 0.22 \\
5 & $\mathbf{7 e}$ & 1.20 \\
6 & $\mathbf{7 f}$ & 5.00 \\
7 & $\mathbf{7 g}$ & 6.70 \\
8 & $\mathbf{7 h}$ & 2.60 \\
9 & $\mathbf{7 i}$ & 19.11 \\
10 & $\mathbf{7 j}$ & 0.33 \\
11 & $\mathbf{1 4 a}$ & 1.24 \\
12 & $\mathbf{1 4 b}$ & 1.41 \\
13 & $\mathbf{1 4 c}$ & 1.11 \\
14 & $\mathbf{1 4 d}$ & 0.69 \\
15 & $\mathbf{1 4}$ & 1.92 \\
16 & $\mathbf{1 4 f}$ & 1.89 \\
17 & $\mathbf{1 4 g}$ & 1.75 \\
18 & $\mathbf{1 4 h}$ & 1.63 \\
19 & $\mathbf{1 4}$ & 2.02 \\
20 & $\mathbf{1 4} \mathbf{j}$ & 2.25 \\
21 & cis-platin & 0.08 \\
\hline
\end{tabular}

3F81) crystal structures available in the Protein Data Bank. A link between VHR and cervical cancer was well established. Compared to normal keratinocytes, VHR protein levels are found to be up regulated in several cervix cancer cell lines including human papilloma virus (CaSki, HeLa, SiHa, HT3 and C33). Biopsies of the primary cervix cancer, squamous intra-epithelial lesions and squamous cell carcinomas of the uterine cervix revealed the higher expression levels of VHR protein level. This clearly suggests that in the treatment of cervical cancer, VHR might be a promising drug target and VHR inhibiting small-molecules could be a potential drug to cure the cervical cancer. ${ }^{17}$

To start with, the reproducibility of docking calculations was verified by extracting the co-crystallized ligand from the complexes and submitted for one-ligand run calculation. This reproduced top scoring conformation falling within root-mean-square deviation (RMSD) value of $1.04 \AA$ with bound X-ray conformation for $3 F 81$, suggesting this method is valid enough to be used for docking studies of other compounds (figure S1 in Supplementary Information). Docking simulation of all the synthesized compounds was performed in the same active site using the same protocol used for the validation study (figure S2 in SI). For each of the test molecules, dockings were performed by taken into 2.5 million energy evaluations. The conformations of docked ligand with VHR receptor were analyzed in terms of energy, hydrogen bonding, hydrophobic and $\pi-\pi$ interaction. The final coordinates of the ligand and 
receptor were saved after the clear analysis of ligandreceptor interactions. To investigate the interactions of ligand and receptor simulated conformations output was exported to PyMOL software. The free energy of binding (FEB) of all compounds were calculated from the docking scores (table 4).

The results revealed that all the docked compounds bind with the receptor and exhibits free energy of binding value between -5.00 and $-8.27 \mathrm{kcal} / \mathrm{mol}$. All the compounds binds in the active site and the simulated conformation exhibits various interactions with 16 amino acids namely LEU-25, PRO-26, PHE-68, MET-69, ASP-92, CYS-124, ARG-125, GLU-126, GLY-127, TYR-128, SER-129, ARG-130, ARG-158, GLY-161, PRO-162 and ASN-163 with non-covalent interactions such as hydrophobic, hydrophilic, $\pi-\pi$ interaction and hydrogen bonding. Among all compounds docked, 7d exhibits very high binding with $3 \mathrm{~F} 81$ receptor and forms two hydrogen bonds with TYR-128 and SER-129 amino acids which resulted in the binding energy of $-6.27 \mathrm{kcal} / \mathrm{mol}$ (figure S6 in SI). In compound 7d, oxygen of $\mathrm{O}-\mathrm{CH}_{3}$ interacts with the hydrogen of $\mathrm{NH}$ of TYR-128 and forms a hydrogen bond with the bond length of $2.7 \AA$. Similarly, oxygen of $\mathrm{O}-\mathrm{CH}_{3}$ interacts with the hydrogen of $\mathrm{NH}$ of SER-129 and forms a hydrogen bond with the bond length of $2.2 \AA$. In addition, benzyl moiety exhibits hydrophobic interaction with GLY-161 and PRO-162 in addition to $\pi-\pi$ interaction with the phenyl ring of TYR-128. It is to be

Table 4. FEB values of compounds on VHR phosphatase receptor.

\begin{tabular}{lcc}
\hline Entry & Compound & FEB $(\mathrm{kcal} / \mathrm{mol})^{\mathrm{a}}$ \\
\hline 1 & $\mathbf{7 a}$ & -6.39 \\
2 & $\mathbf{7 b}$ & -6.26 \\
3 & $\mathbf{7 c}$ & -6.67 \\
4 & $\mathbf{7 d}$ & -8.27 \\
5 & $\mathbf{7 e}$ & -6.13 \\
6 & $\mathbf{7 f}$ & -6.45 \\
7 & $\mathbf{7 g}$ & -6.43 \\
8 & $\mathbf{7 h}$ & -5.67 \\
9 & $\mathbf{7 i}$ & -6.25 \\
10 & $\mathbf{7 j}$ & -6.07 \\
11 & $\mathbf{1 4 a}$ & -5.89 \\
12 & $\mathbf{1 4 b}$ & -5.86 \\
13 & $\mathbf{1 4 c}$ & -6.10 \\
14 & $\mathbf{1 4 d}$ & -7.27 \\
15 & $\mathbf{1 4 e}$ & -5.17 \\
16 & $\mathbf{1 4 f}$ & -5.00 \\
17 & $\mathbf{1 4 g}$ & -6.31 \\
18 & $\mathbf{1 4 h}$ & -6.47 \\
19 & $\mathbf{1 4 i}$ & -6.77 \\
20 & $\mathbf{1 4 j}$ & -6.51 \\
\hline
\end{tabular}

${ }^{\mathrm{a} F r e e}$ energy of binding (PDB ID: 3F81) noted that compound 7d with highest binding energy $(-8.27 \mathrm{kcal} / \mathrm{mol})$ did exhibit significant $\mathrm{IC}_{50}$ value $(0.22 \mu \mathrm{M})$, thus establishing a correlation with the biological results.

\section{Conclusions}

In continuation to our previous work on the synthesis of pyrano[3,4- $b$ ]indol-1 $(9 H)$-ones, we further extended our studies towards the synthesis of the corresponding pyrano[4,3- $b]$ indol-1 $(5 H)$-ones. The synthetic potential of gold(III) chloride in the flexible synthesis of isomeric pyranoindolones in excellent regioselectivity and good chemical yields was also demonstrated. All compounds were evaluated for their cytotoxic potency towards HeLa cells and compared with the reference drug cis-platin. The results of which indicated that three candidates $\mathbf{7 d}, \mathbf{7 j}$ and $\mathbf{1 4 d}$ exhibited significant inhibitory potency with $\mathrm{IC}_{50}$ values of $0.22,0.33$ and $0.69 \mu \mathrm{M}$, respectively. Molecular docking with VHR phosphatase receptor also supported the biological results by showing compound $\mathbf{7 d}$ as the most active with a free energy of binding $-8.27 \mathrm{kal} / \mathrm{mol}$. Further investigations to delineate the scope and limitations of the current protocol to biologically active natural products are actively underway in our laboratory and the results will be disclosed in the due course.

\section{Supplementary information (SI)}

Copies of molecular docking pictures, ${ }^{1} \mathrm{H}$ NMR, ${ }^{13} \mathrm{C}$ NMR and mass spectra of selected compounds are provided in the Supplementary Information, which is available at www.ias.ac.in/chemsci.

\section{Acknowledgements}

C.P. gratefully acknowledges the Science and Engineering Research Board (SERB), India for providing Fast Track award under Young Scientist Scheme (SERB/ F/5666/2015-16). C.P. extends his acknowledgement to Dr. Vijayamohanan K. Pillai, Director, CSIR-CECRI and Dr. D. Jeyakumar, Head, Functional Materials Division, CSIR-CECRI for providing infrastructure facilities.

\section{References}

1. (a) Fürstner A 2014 Acc. Chem. Res. 47 925; (b) Hashmi A S K and Rudolph M 2008 Chem. Soc. Rev. 37 1766; (c) Zhang Y, Luo T and Yang Z 2014 Nat. Prod. Rev. 31 489 
2. (a) Hashmi A S K, Schwarz L, Choi J-H and Frost T M 2000 Angew. Chem. Int. Ed. 39 2285; (b) Hashmi A S K, Frost T M and J W Bats $2000 \mathrm{~J}$. Am. Chem. Soc. 122 11553

3. (a) Praveen C, Karthikeyan K and Perumal P T 2009 Tetrahedron 65 9244; (b) Praveen C, Kalyanasundaram A and Perumal P T 2010 Synlett 777; (c) Praveen C and Perumal P T 2011 Synlett 521; (d) Praveen C, Ayyanar A and Perumal P T 2011 Bioorg. Med. Chem. Lett. 21 4170; (e) Praveen C and Perumal P T 2016 Chin. J. Catal. 37 288; (f) Jeyaveeran J C, Praveen C, Arun Y, Prince A A M and Perumal P T 2016 J. Chem. Sci. 128 73; (g) Praveen C, Sagayaraj Y W and Perumal P T 2009 Tetrahedron Lett. 50 644; (h) Praveen C, Kiruthiga P and Perumal P T 2009 Synlett 1990; (i) Praveen C, Jegatheesan S and Perumal P T 2009 Synlett 2795; (j) Praveen C and Perumal P T 2016 Synthesis 48 855; (k) Praveen C, Dheenkumar P, Muralidharan D and Perumal P T 2010 Bioorg. Med. Chem. Lett. 20 7292; (1) Praveen C, Ayyanar A and Perumal P T 2011 Bioorg. Med. Chem. Lett. 21 4072; (m) Praveen C, Iyyappan C, Girija K, Kumar K S and Perumal P T 2012 J. Chem. Sci. 124 451; (n) Praveen C, Nandakumar A, Dheenkumar P, Muralidharan D and Perumal P T 2012 J. Chem. Sci. 124 609; (o) Praveen C, Narendiran S, Dheenkumar P and Perumal P T 2013 J. Chem. Sci. 125 1543; (p) Praveen C, Dheenkumar P and Perumal P T 2013 J. Chem. Sci. 125 71; (q) Parthasarathy K, Praveen C, Balachandran C, Kumar P S, Ignacimuthu S and Perumal P T 2013 Bioorg. Med. Chem. Lett. 23 2708; (r) Parthasarathy K, Praveen C, Kumar P S, Balachandran C and Perumal P T 2015 RSC Adv. 5 15818; (s) Praveen C, Iyyappan C, Perumal P T and Girija K 2012 Ind. J. Chem. 51B 498; (t) Praveen C, Parthasarathy K, Kumar, P S and Perumal P T 2015 Ind. J. Chem. 54B 373

4. Shimizu M, Hirano K, Satoh T and Miura M $2009 \mathrm{~J}$. Org. Chem. $\mathbf{7 4} 3478$
5. Suresh R R and Swamy K C K 2012 J. Org. Chem. 77 6959

6. Ngi S I, Guilloteau V, Abarbri M and Thibonnet J 2011 J. Org. Chem. 768347

7. Agnusdei M, Bandini M, Melloni A and Umani-Ronchi A 2003 J. Org. Chem. 687126

8. (a) Choshi $T$, Sada $T$, Fujimoto $H$, Nagayama C, Sugino E and Hibino S 1997 J. Org. Chem. 62 2535; (b) Sakamoto T, Nagano T, Kondo Y and Yamanaka H 1988 Chem. Pharm. Bull. 362248

9. (a) Sechi M, Derudas M, Dallocchio R, Dessí A, Bacchi A, Sannia L, Carta F, Palomba M, Ragab O, Chan C, Shoemaker R, Sei S, Dayam R and Neamati N 2004 J. Med. Chem. 47 5298; (b) Tsotinis A, Afroudakis P A, Davidson K, Prashar A and Sugden D 2007 J. Med. Chem. 506436

10. Sonogashira K, Tohda Y and Hagihara N 1975 Tetrahedron Lett. 164467

11. Marchal E, Uriac P, Legouin B, Toupet L and van de Weghe P 2007 Tetrahedron 639979

12. Somei M, Sayama S, Naka K, Shinmoto K and Yamada F 2007 Heterocycles 73537

13. Travis B R, Sivakumar M, Hollist G O and Borhan B 2003 Org. Lett. 51031

14. (a) Alley M C, Scudiero D A, Monks A, Hursey M L, Czerwinski M J, Fine D L, Abbott J G M, Shoemaker R H and Boyd M R 1988 Cancer Res. 48 589; (b) Mossman T 1983 J. Immunol. Methods 6555

15. Williams D H, Stephens E, O'Brien D P and Zhou M 2004 Angew. Chem. Int. Ed. 436596

16. (a) Morris G M, Huey R, Lindstrom W, Sanner M F, Belew R K, Goodsell D S and Olson A J 2009 J. Comput. Chem. 30 2785; (b) Sanner M F 1999 J. Mol. Graphics Mod. 1757

17. Wu S, Vossius S, Rahmouni S, Miletic A V, Vang T, Vazquez-Rodriguez J, Cerignoli F, Arimura Y, Williams S, Hayes T, Moutschen M, Vasile S, Pellecchia M, Mustelin T and Tautz L 2009 J. Med. Chem. 526716 